\title{
EXAMINING CLINICIAN ATTITUDES ON SEXUAL HEALTH ASSESSMENT AFTER AN EDUCATIONAL INTERVENTION
}

\author{
A Scholarly Project \\ submitted to the Faculty of the \\ Graduate School of Arts and Sciences \\ of Georgetown University \\ in partial fulfillment of the requirements for the \\ degree of \\ Doctor of Nursing Practice
}

By

Jenna Benyounes, M.S.

Washington, DC

November 17, 2017 
Copyright 2017 by Jenna Benyounes All Rights Reserved 


\title{
EXAMINING CLINICIAN ATTITUDES ON SEXUAL HEALTH ASSESSMENT AFTER AN EDUCATIONAL INTERVENTION
}

\author{
Jenna Benyounes, M.S. \\ Thesis Advisor: Julia Lange Kessler, D.N.P.
}

\begin{abstract}
It is estimated that $43 \%$ of women suffer from sexual dysfunction. Women expect their providers to evaluate their sexual health, yet most clinicians do not because they feel they do not have the time, training, or knowledge of sexual health. This discrepancy leaves many women with unaddressed health concerns. The purpose of the study was to 1) examine clinician attitudes before and after watching an evidence-based educational video 2) examine the impact of each of the six educational domains individually and to 3 ) assess the correlation between the participants quality rating of each domain in the video and impact the on participants' attitudes. A recruitment email was sent to one primary care practice and two ob/gyn practices in the Washington, D.C. area. Participants were asked to forward the survey to appropriate colleagues to widen and diversify the sample. Participants completed a 12 question pre-survey. A majority then watched a 15 minute evidence-based educational video about women's sexual health that included the following domains: how to ask and evaluate sexual health, how to address concerns, what a sexual medicine specialist/pelvic floor physical therapist/sexuality mental health professional does, and how to find them and available resources (organizations, websites, and continuing education). After watching the video, participants took a 17 question post-survey. Before and after t-scores demonstrated a significant improvement in provider willingness to evaluate sexual health. Each domain of the video made a positive impact. 93-98\% of participants "somewhat agreed" to "strongly agreed" that each domain made them more likely to evaluate their patient's sexual health. The higher a respondent rated a domain, the more likely they were
\end{abstract}


to believe they were more likely to evaluate their patients' sexual health, as demonstrated by a correlation coefficient of 0.6 to 0.7 . Participants who finished both the pre-survey and postsurvey rated themselves lower on screening behaviors in the pre-survey, demonstrating the significant impact of the video. An evidence-based educational video containing basics of evaluation of women's sexual health and available resources led to improved provider belief that they would evaluate women's sexual health, thus addressing more women's sexual health and possible dysfunction. 


\section{ACKNOWLEDGEMENTS}

They say it takes a village...Dedicated to past, present, and future patients of women's health. May you have a comprehensive, compassionate, and inspired experience you're your healthcare.

To my team. Dr. Julia Lange Kessler, thank you for "midwifing" me through this whole process. You knew exactly how to give me the support I needed while pushing me to grow at the same time. I appreciated your patience, guidance and "being with me." I'd also like to thank Dr. Maryanne Lachat for your support and enthusiasm for not only this project but for women and their families. Lastly, thank you to Dr. Andrew Goldstein. Your dedication to the field of sexual medicine and your scientific brilliance is an inspiration. It was an honor to have you on my team.

To my renaissance brother, Shawn Benyounes. This honestly is your project as well. I do not know what I would have done without you. Your ever-present genius, and technology and reading skills were invaluable. Thank you for always being available to help me, and save the day, especially when I was about to lose it. I'm so proud to call you my brother.

To Mom and Dad. I'm everything I am because of the love, support, and encouragement you have always given me. I would not be here without you. Words cannot thank you enough. I love you.

To Chris. Thank you for supporting me through all of my crazy ideas, including going back to school for a doctorate degree while working lots of jobs. It takes a strong person to not see their partner as often, deal with them being exhausted or preoccupied. You sacrificed along the way with me. Thank you for supporting me in pursuing my dreams. I love you.

To my fur babies, Chanel, Oliver and George. Thank you for your warm cuddles, always being excited to see me when I got home when I was gone, keeping me company at all hours while I worked, being good listeners, and being my best friends.

To the midwives and physicians in OB/GYN at the George Washington University. Thank you for your support and encouragement during this process. GW is a place of compassionate evidence-based medicine, thank you for making and keeping that dream a reality. Thank you for being the starting point for my survey. To Dr. Nancy Gaba, Ms. Claire Rodriguez and Ms. Tammy Blair, thank you for your willingness to email the survey to your organizations. Thank you to Ms. Tracy Sher for wisdom and support.

Thank you to the participants who took the time to complete the study. Without you, we couldn't be the start of a change for the course of care for women. An additional thank you to the participants who sent the survey to colleagues and friends to complete.

To my family and friends. Thank you for understanding when I was not around, even though you were. Thank you for all of your encouragement and belief in me. It kept me going.

To the faculty at Georgetown. You all are so inspiring. Thank you for sharing your wisdom and knowledge. To Dr. Slota, for your vision and dedication to the program, as well as your calm and peaceful energy. To my study buddies, Courtney and Danielle. The tomato timer, the dance breaks, answering my texts to keep me on track, the support. I do not know what I would have done without you two. To the DNP 12 pack, the best part of this process. I'm so very impressed by each of you. Thank you all for your inspiration, encouragement, brilliant conversations and friendship. I'm so honored to have been on this journey with you, I wouldn't have made it without you. I know we will make a difference and I'm excited to see how we change the world! 


\section{TABLE OF CONTENTS}

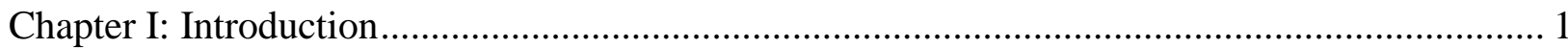

Description and Statement of Problem ........................................................................ 2

Background and Significance of the Problem ............................................................... 2

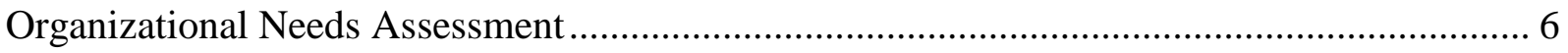

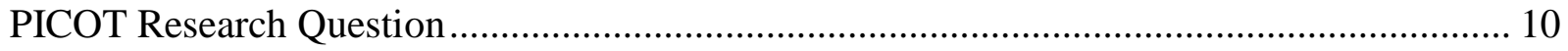

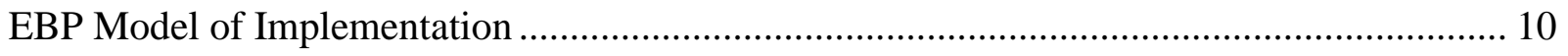

Theoretical Framework ........................................................................................ 11

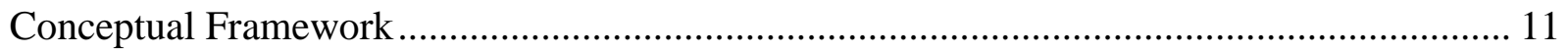

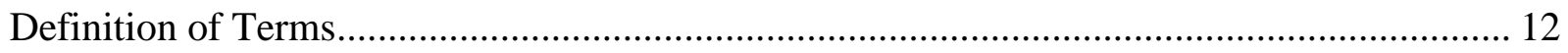

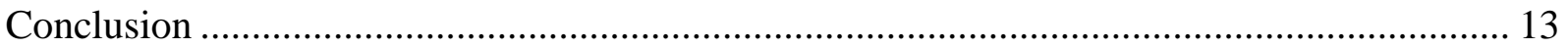

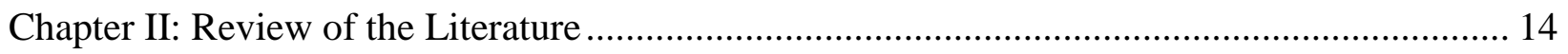

Introduction to Search Criteria.................................................................................. 14

Critique and Synthesis of Previous Evidence ............................................................ 15

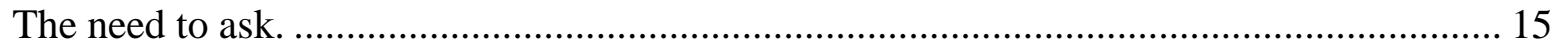

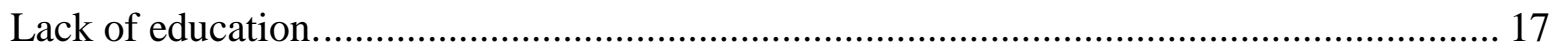

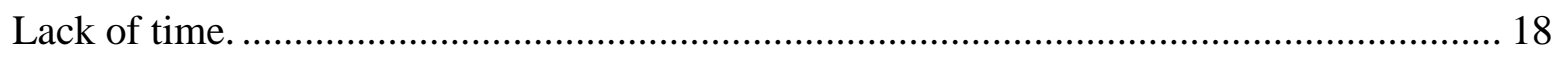

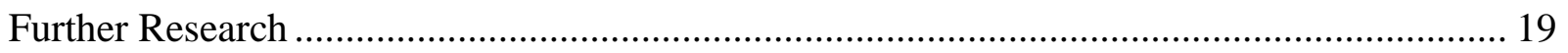

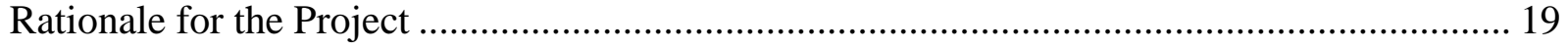

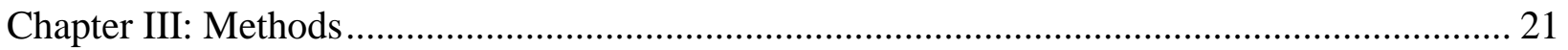




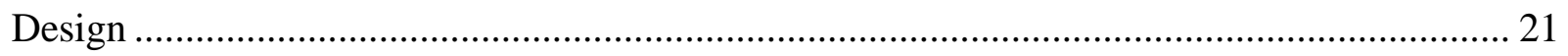

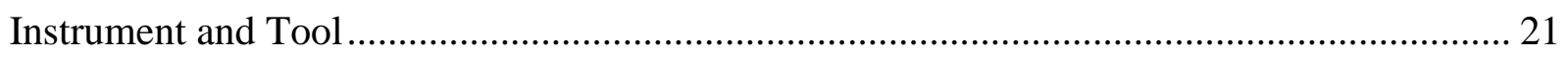

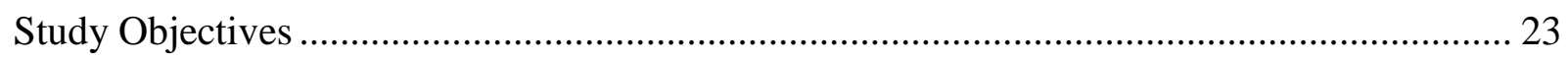

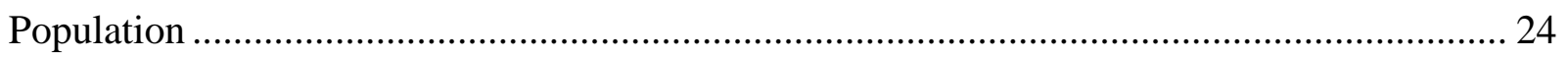

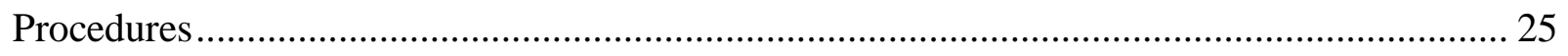

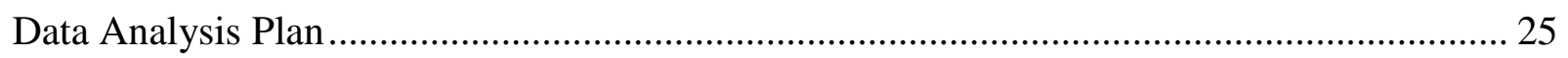

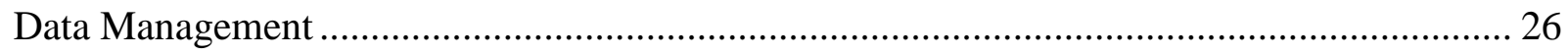

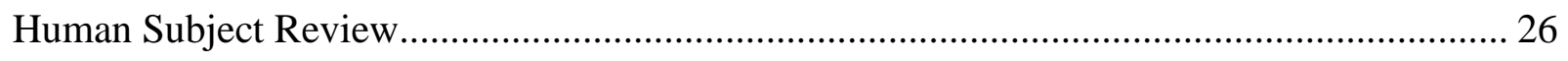

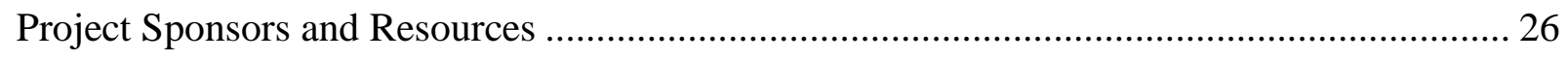

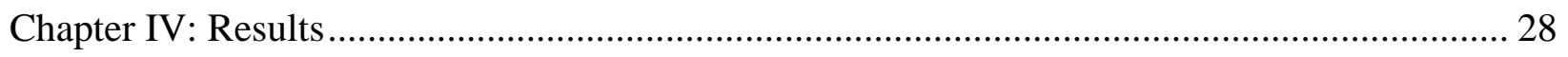

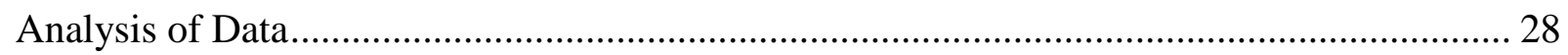

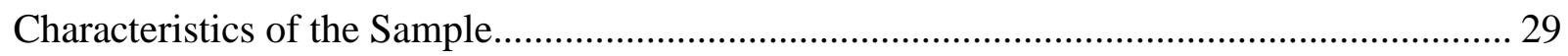

Participants' Attitudes Before and After Watching the Video ............................................... 31

Evaluation of Participants' Quality Rating of Each Domain................................................... 34

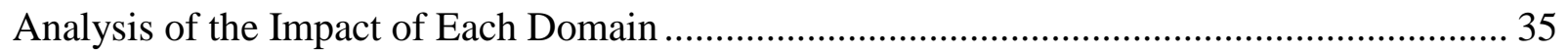

Analysis of Participants' Quality Rating of Each Domain and the Impact on Participant's

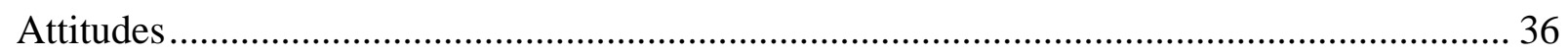

Summary of Findings and Outcomes..................................................................................... 37

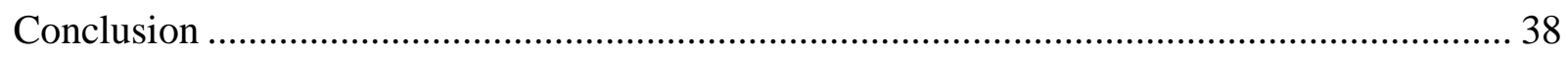

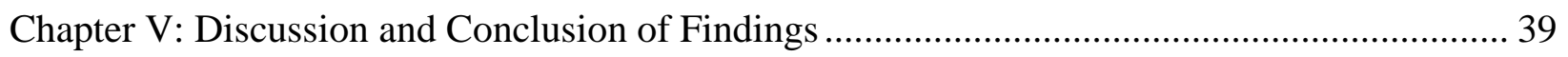


Participants' Attitudes Before and After Watching the Video .....

Evaluation of Participants' Quality Rating of Each Domain.............................................. 41

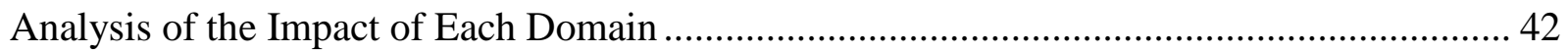

Analysis of Participants' Quality Rating of Each Domain and the Impact on Participant's

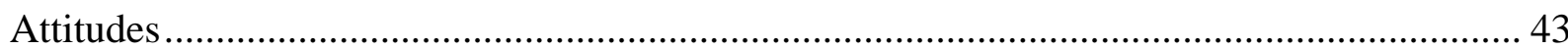

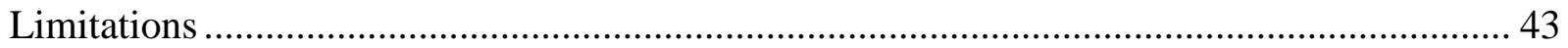

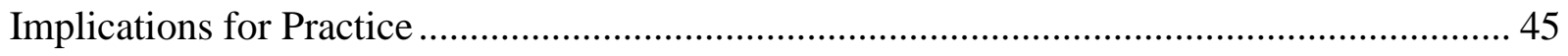

Recommendations for Further Study ................................................................... 45

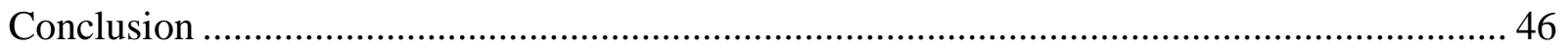

Appendix A: Iowa Model for Evidence-Based Practice .................................................. 48

Appendix B: Non-Linear Model of Female Sexual Response................................................. 49

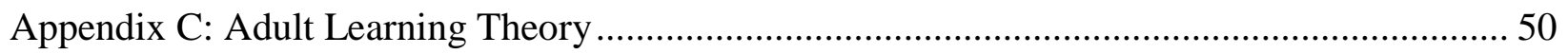

Appendix D: Melnyk Levels of Evidence ................................................................. 51

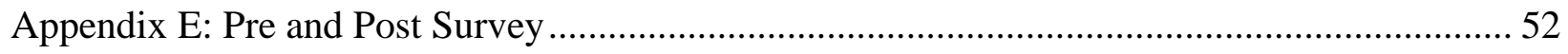

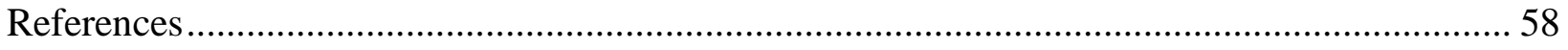




\section{LIST OF TABLES}

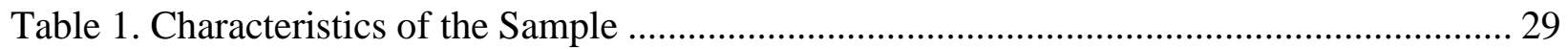

Table 2. Pre-Survey Post-Survey Overall Impact ........................................................... 31

Table 3. Pre-Survey vs. Post-Survey Impact on Comfort................................................... 32

Table 4. Pre-Survey vs. Post-Survey Impact on Knowledge................................................ 32

Table 5. Evaluation of Participants' Quality Rating of Each Domain..................................... 34

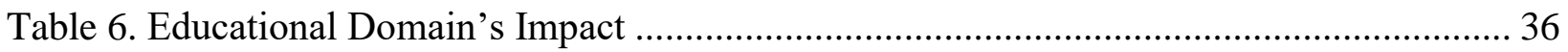

Table 7. Correlation of Video Quality and Impact on Participants' Attitudes by Domain .......... 37 


\section{Chapter I: Introduction}

Sexual health, as defined by the World Health Organization (2006), is:

A state of physical, emotional, mental and social well-being in relation to sexuality; it is not merely the absence of disease, dysfunction or infirmity. Sexual health requires a positive and respectful approach to sexuality and sexual relationships, as well as the possibility of having pleasurable and safe sexual experiences, free of coercion, discrimination, and violence. For sexual health to be attained and maintained, the sexual rights of all persons must be respected, protected and fulfilled.

Sexual dysfunction impacts an estimated $43.1 \%$ of women in the United States (Shifren, Monz, Russo, Segreti, \& Johannes, 2008). Many of these women do not have their concerns addressed because they are embarrassed to ask their clinician. They expect their healthcare provider to initiate the discussion about sexual health. However, healthcare providers often do not initiate the conversation or know how to properly address a patient's concerns. Reasons for not screening include lack of time, lack of education, and lack of knowledge (Kingsberg \& Knudson, 2011).

The purpose of this research is to examine whether providing clinicians with education and resources about sexual health and dysfunction would impact their perceived future behaviors for completing a sexual health evaluation for their patients. This section of the paper includes background information of the problem, the significance, an organizational needs assessment, PICOT question, the evidence-based practice model, the theoretical frame work utilized, and the definition of terms in context of the study. 


\section{Description and Statement of Problem}

Sexual dysfunction is a multifactorial phenomenon that involves biology, psychology, relationships, societal and cultural factors (Clayton \& Groth, 2013). Sexual health and general health are often related. Women who suffer from sexual dysfunction are more likely to have depression, anxiety, hypertension, diabetes, and elevated lipids (Sadovsky \& Nusbaum, 2006). Shifren et al. (2009) reported in their study that $78 \%$ of patients expected their healthcare provider to ask them about their sexual health, especially when they were in the care of a gynecologist or primary care physician.

There are numerous studies that state the most common reason providers do not routinely evaluate their patients' sexual health and dysfunction is a lack of time (Abdolrasulnia et al., 2010; Garcia \& Fisher, 2008; Kingsberg \& Knudson, 2011; Roos, Thakar, Sultan, \& Scheer, 2009). In addition to lack of time, other reasons for not evaluating are their lack of knowledge and training on the subject (Dahir, 2009; Kingberg \& Knudson, 2011; Roos, Sultan, \& Thakar, 2012; Rosen, Kountz, Post-Zwicker, Leiblum, \& Wiegel, 2006; Wittenberg \& Gerber, 2009). In the review of the literature, no studies were found that assessed what intervention could increase provider evaluation of sexual health and dysfunction, while being mindful of the perceived barriers.

\section{Background and Significance of the Problem}

The prevalence of sexual concerns in women is high and varied (Kingsberg \& Althof, 2009). The four categories of sexual dysfunction include disorders of sexual desire, sexual arousal, orgasm, and pain (Bornstein et al., 2016). These disorders are psychological and physiological in origin and are not mutually exclusive (Khajehei, Doherty, Tilley, \& Sauer, 2015). 
Both patients and women's health care providers find the topic of sexual health to be important. Of primary care, obstetrics and gynecology physicians surveyed, $89 \%$ believed that screening for female sexual dysfunction was somewhat or very important (Nusbaum, Gamble, Skinner, \& Heiman, 2000). Shifren et al. (2009) reports that $78 \%$ of patients expect their provider to ask them about their sexual health. In a study by the Association of Reproductive Health Professionals and the National Women's Health Resource Center (2009), they found that $74 \%$ of providers relied on their patients to initiate a discussion about their sexual health, yet, $73 \%$ of patients preferred that their healthcare provider brought up the topic (Association of Reproductive Health Professionals and the National Women's Health Resource Center, 2009). Sixty-eight percent of patients wanted a provider who appeared comfortable evaluating their sexual health and addressing their concerns (Nusbaum et al., 2000). In the office, it was found that $69 \%$ of physicians underestimated female sexual dysfunction in their patients (Goldenhar et al., 2005).

Sexuality fulfills an array of personal, reproductive, and social needs (Satcher, Hook \& Coleman, 2015). While many clinicians believe sexuality is only a social construct, sexual health is just as important as general health. Women who suffer from sexual dysfunction often have comorbid issues. These issues include but are not limited to depression, psychosocial stress, cardiovascular disease, hypertension, diabetes, hyperlipidemia, hyperprolactinemia, and low serum testosterone (Sadovsky \& Nusbaum, 2006). Orgasms and intimacy increase oxytocin. This has been found to lower the risk of heart disease, stroke, breast cancer, and depression. It can also aid with sleep, decrease stress, increase social abilities, improve the immune system, and decrease pain (Cardoso, Ellenbogen, Serravalle, \& Linnen, 2013; Ellison, 2000; Grewen \& 
Light, 2011; Welch, Margolis, Li, \& Gershon, 2014; Whipple, Knowles, Davis, Gianotten, \& Owens, 2007; Whipple \& Komisaruk, 1988; Williams \& Reynolds, 2006).

The most recent publication to estimate the cost of chronic pelvic pain was published in 1996. At the time, it was estimated that chronic pelvic pain cost the United States 2.8 billion dollars annually in direct cost (Mathias, Kuppermann, Liberman, Lipschutz, \& Steege, 1996). Women with chronic pelvic pain took three times the amount of prescription medications as pain free women and were more likely to have had major and minor surgeries; thus, increasing direct and indirect costs (Collett, Cordle, Stewart, \& Jagger, 1998). More recently, a publication solely about the cost of endometriosis, estimated an annual cost of $\$ 11,777$ dollars. Approximately one third of the cost, $\$ 3,953$ dollars, were health care costs. The additional $\$ 7,747$ dollars, was the cost of lost productivity (Simoens et al., 2012).

The 2015 International Society for the Study of Vulvovaginal Disorders (ISSVD), International Society for the Study of Women's Sexual Health (ISSWSH), and International Pelvic Pain Society (IPPS) consensus statement define vulvodynia as "vulvar pain of at least three months' duration, without clear identifiable cause, which may have potential associated factors" (Bornstein et al., 2016). Annually, the cost of vulvodynia, per patient, is $\$ 17,700$ dollars in direct and indirect costs. The average amount of time it takes a patient to have a diagnosis and appropriate treatment is seven years. It is estimated that the annual national financial cost to vulvodynia is between $\$ 31$ billion and $\$ 72$ billion dollars (Xie, Shi, Xiong, Veasley, \& Dade, 2012). These figures only report the financial cost, and do not reference women with other types of sexual dysfunction such as decreased desire, arousal, orgasm, lubrication, and satisfaction.

One way to decrease healthcare costs is to increase providers' understanding of sexual dysfunction and what resources are available to providers and patients alike. Wittenberg and 
Gerber (2009) found that "The majority of medical students...68.8\% feel that addressing and treating sexual concerns will be an important part of their future careers, and only $37.6 \%$ feel adequately trained to do so." If education regarding sexual health concerns and resources is improved with healthcare professionals, the knowledge can assist them in providing patients with a proper diagnosis, treatment plan, anticipatory guidance, and/or proper referral. This can potentially decrease the amount of unproductive, and demoralizing appointments that patients will have because they will be appropriately referred to a provider who can assess and treat them for their concerns.

The Hippocratic Oath states that providers have an ethical obligation of beneficence, which means to do good, and non-maleficence, which means do no harm (Edelstein, 1943). In addition, the ethical principle of respect for autonomy is essential in healthcare. According to the University of California, San Francisco School of Medicine (2008), "autonomous individuals act intentionally, with understanding, and without controlling influences." In order to meet the ethical obligations that providers owe to patients, the patient must be provided thoughtful, accurate, evidence-based information. Due to the lack of education regarding sexuality in the curriculum of medical professionals, it would behoove the provider to seek out reputable, quality, current information sources when guiding their practice. However, some providers counsel patients on antiquated data, anecdotal data, or do not have enough information to provide patients with the true benefits and risks for each situation.

In 2010, an article published in the Journal of the American Medical Association (JAMA), proposed a national shift from focusing on disease to a focus on health (Swartzendruber \& Zenilman, 2010). More recently, this recommendation is being implemented. Unlike previous Healthy People initiatives, Healthy People 2020 (n.d.) addresses reproductive 
and sexual health with an emphasis on wellness. This is congruent with the recommendations from experts who believe "we can only meet the sexual health challenges by shifting away from the current focus on diseases and moving towards a perspective that promotes health and wellness" (American Sexual Health Association, n.d.). To move this concept forward, Satcher, Hook, and Coleman (2015) created a framework that emphasizes wellness, focus on positive and respectful relationships, acknowledgment of sexual health as an element of overall health, and an integrated approach to prevention.

Legally, gynecology and obstetrics is one of the most litigious disciplines of medicine (Jena, Seabury, Lakdawalla, \& Chandra, 2011). Being able to provide women with thorough care and appropriate referral is imperative. It is a fundamental ethical obligation. Not screening for sexual health concerns can create a myriad of problems for patients that can have life-long implications.

Given that sexual health and dysfunction is common, important to women, and impacts their general health, it is vital to improve education and knowledge of resources for healthcare providers who serve women.

\section{Organizational Needs Assessment}

A detailed organization needs assessment was completed on the academic OB/GYN practice in which the researcher worked, as this would be one of the three practices to disseminate the researcher's study recruitment email. The purpose of the needs assessment was to evaluate the skill gaps that were reported in the review of the literature were congruent with the clinical practice in the organization. It was also completed to create strategies that would improve the implementation of the study within the context of the organization. 
The organizational culture is very supportive of research. It is an academic practice in Washington, DC, that is affiliated with a university and academic hospital. Being in the setting of academia, the organization is well versed in facilitating and conducting research. Two ambulatory care offices are located in Washington, D.C. and one office is in Bethesda, Maryland. The organization is associated with an academic institution, and is comprised of 750 nurse practitioners, physician assistants, certified nurse midwives, and physicians. Approximately 50 healthcare providers work in the department of OB/GYN where the survey will be distributed by email. Being in a practice of this size affords the researcher a large sample size of potential participants. Since participants work in academia, they may see more value in research, and may be more willing to share the invitation email with other professional colleagues.

Continuing education is important within the organization. All providers are expected to attend weekly grand rounds presentations. Within the provider's benefits package is a monetary allowance for continuing education. Due to the academic model and busy provider schedule, there are no in-services provided within the organization. Professional development is considered a professional duty and is not considered part of the 40-hour work week for providers.

Organizational culture is comprised of assumptions and behaviors that are learned as a result of adaptation. Schein's (2010) levels of cultural theory include artifacts, values, and basic underlying assumptions. All three components of Schein's theory of organizational culture are evaluated below in the context of the organization where the research was conducted.

Artifacts are visible components of culture in the organization which include rituals, symbols and slogans (Schein, 2010). The most easily noticed artifact are what can be seen such as is the remodeled lobby and exam rooms with a calm décor with highlights of the color pink. 
Healthcare providers wear business casual dress and wear a custom white coat with their name and credentials embroidered. The badge holders provided by the practice say "Respect. Compassion. Collaboration. Because we care." Other artifacts, can be observed through ritual. Healthcare providers call each other by their first names. Some of the nurses will call the physicians by their first name as well. Patients call the physicians "doctor" and refer to other healthcare providers by their first names.

Values are the behaviors an organization desires to promote. Superficially, values are first seen through artifacts such as slogans on badge holders, however, true values are observed through employee behaviors and opinions (Schein, 2010). The values promoted by the organization are collaboration, communication, following policies and procedures, research, and promoting education. All providers collaborate with each other in a respectful, professional manner. There is a sense that each provider brings value to the organization. There are mandatory courses for improving communication. These courses teach professional communication styles to decrease hierarchical thinking and to provide safer patient care. Upon hire, a manual given to each new employee on the policies and procedures of the organization. These policies and procedures are followed, and enforced, to hold everyone to the same standard and create more uniformity in a large organization. The organization is partnered with the university and hospital so there are often students present. Within the community, the organization is known as a teaching institution and it is proudly displayed on many pages of the website. Research is important because most of the staff hold faculty positions at the university and are required to participate in research. While research is a significant component of academic medicine, there are barriers to research within the organization. Enthusiasm, participation, and awareness of research could be stronger. Optional research meetings for those 
interested in research are often held in the middle of the day when most healthcare providers are working. Many times, providers learn of each other's research by chance as there is no formal announcement or recruitment of research studies that are occurring. It could be helpful to have more awareness in the organization of what research is going on, what research can be done, and how providers can get involved, even at the most basic level.

According to Schein (2010), basic underlying assumptions are unspoken, yet understood, and deepest component of culture. To understand the basic underlying assumptions is to understand the culture of the organization. The primary basic underlying assumption of the organization is that the patient comes first. Providers are expected to go out of their way to satisfy the patient's needs and to coordinate care. Even though the midwife position is considered a standard 40-hour work week, providers contribute more than 40 hours a week. Because much of the provider's time is utilized for patient care and administrative work, participating in research may be difficult due to time constraints. An underlying assumption that may assist in facilitating research, even with time constraints, is the assumption of collaboration. This assumption drives compassion and teamwork between colleagues. If approached and given the information, there could abundance of providers who would participate in a colleague's research study.

In summary, the organizational assessment identified strengths and challenges. Two compelling strengths include the setting of academia supporting research, as well as the teamwork and support of colleagues within the organization. Healthcare providers with a lack of time to engage in the research study are the biggest barrier or challenge. Based on the organizational needs assessment, the organization would be a suitable, and appropriate, environment to implement the DNP project. As an academic institution, resources for research 
are abundant. These resources would include access to library databases, fellow researchers who can mentor each other, an IRB, and a statistician. The organization is very proud of any published research and would most likely use a public relations campaign to make others aware of the research being generated within the organization. If all goes well, this would encourage the organization to endorse and encourage more sexual health research in the future.

\section{PICOT Research Question}

PICOT is an acronym that stands for patient population, intervention, comparison, outcome, and time frame. It is a means to format a succinct clinical question that guides the review of the literature before proceeding with a research study (Melnyk, \& Fineout-Overholt, 2015). The PICOT question based on the phenomena of interest is: how does providing clinicians with evidence-based education and resources, regarding sexual health and dysfunction, impact their attitudes and perceived future screening behaviors?

\section{EBP Model of Implementation}

An evidence-based practice (EBP) model is a model used to help translate research outcomes into clinical practice. The Iowa Model (Appendix A) considers the whole healthcare system in its approach. The first step is to acknowledge a clinical problem trigger or knowledge trigger. Next is to evaluate if the problem is a priority for the organization. If it is not, a new trigger needs to be explored. If it is, the researcher will create a team, search, and then appraise the literature. If there is a sufficient literature based intervention, the researcher can pilot the changes in practice. If there is not sufficient evidence, then research is conducted (Titler et al., 2001). 


\section{Theoretical Framework}

The literature on "sexual function" is not well defined. Rather, the literature reflects a larger knowledge base related to "sexual dysfunction." Sexual dysfunction previously was defined by Kaplan (1977), as a disturbance in the physiological process of desire, arousal, and orgasm. The non-linear model for sexual response, by Dr. Basson, will be utilized as a theoretical frame work (Appendix B). Basson et al. (2004) produced a sentinel article, written by women's healthcare providers and psychologist, to redefine sexual dysfunction that accounts for physical and emotional reasons for sexual dysfunction. With this non-linear model, biological factors, physiological factors, sexual stimuli, sexual arousal, sexual drive, emotional and physical satisfaction, emotional intimacy, and spontaneous sexual drive all play a role in sexual response. This model accounts for dysfunction with desire, arousal, orgasm, satisfaction, and pain. It does not correlate sexual satisfaction solely to an orgasm. Any disturbance, physiologically or psychologically, is considered sexual dysfunction (Basson et al., 2004). Thus, it can be extrapolated that sexual function is the absence of disturbance in desire, arousal, orgasm, satisfaction, and a lack of pain. This model is the foundation for the educational video that will be created. It emphasizes a team approach to address the bio-psychosocial aspects of female sexual health.

\section{Conceptual Framework}

The study was conceptualized with the Adult Learning Theory (Appendix C), Andragogy, the art and science of helping adults learn, by Malcolm Shepherd Knowles (1984). Adult Learning Theory has two parts, the assumptions made of adult learners and the principles of Andragogy. Assumptions about the adult learner include that they: "Move from dependency to increasing self-directedness as he/she matures and can direct his/her own learning; Draw on 
his/her accumulated reservoir of life experiences to aid learning; Are ready to learn when he/she assumes new social or life roles; Are problem-centered and want to apply new learning immediately; Are motivated to learn by internal, rather than external, factors" (Teaching Excellence in Adult Literacy, 2011, p.1). Principles of adult learning include: Involving the adult learner in the planning and evaluation of instruction; experience is the foundation for learning; adults are interesting in learning things that impact their job or life; and that the learning is problem centered compared to content only (Knowles, 1984).

The principles of adult learning were utilized in creation of this study. To involve learners in the instruction, a literature review was completed to explore clinician sexual health assessment perceptions, barriers, and knowledge. This was done to understand the gaps in knowledge and what knowledge could potentially make a difference for clinicians. While direct experience was not able to be utilized in the study, the video included scripted examples of interactions that could occur with patients. A follow up study will include actual live experiential learning and the outcomes that result from it. Another component of the Adult Learning Theory is that adults want to learn things that will impact their job. Given that all participants of the study were clinicians, and the education is related to their work, it easily satisfies that component of the Adult Learning Theory. Lastly, in agreement with the theory, the education was problem centered rather than providing only content and statistics.

\section{Definition of Terms}

Sexual Health: a state of physical, emotional, mental and social well-being in relation to sexuality; it is not merely the absence of disease, dysfunction or infirmity (World Health Organization, 2006) Sexual Function: lack of disturbance of desire, arousal, lubrication, satisfaction, pain, or orgasm (Basson, 2004) 
Sexual Dysfunction: disturbance of desire, arousal, lubrication, satisfaction, pain, or orgasm (Basson, 2004)

Attitudes: the way a person thinks and feels about someone or something (Attitude, n.d.)

Behaviors: the way a person or animal acts or behaves (Behavior, n.d.)

Evaluate: to determine the significance or condition of usually by careful appraisal and study

(Evaluate, n.d.)

Clinician: Advanced Practice Nurse (Nurse Practitioner, Certified Nurse Midwife),

Physician Assistant, Physician, Physical Therapist, Mental Health Professional

\section{Conclusion}

Sexual health is an important aspect of the patient healthcare experience that has a significant impact on their life. Health care providers feel unable to properly address patient question or concerns due to lack of time, education, and knowledge. Completing an evidencebased educational intervention and providing healthcare professionals with resources may increase the evaluation of sexual dysfunction and thus lead to more patients having their concerns addressed. 


\section{Chapter II: Review of the Literature}

\section{Introduction to Search Criteria}

A comprehensive review of the literature was completed. The purpose was to find all relevant and up to date articles published that related to the impact on education and resources for healthcare providers, and its effect on their attitudes and behaviors, in regard to screening for sexual health. In addition, articles were found to explain sexual function and dysfunction.

Databases utilized were PubMed, CINAHL, and Embase. These databases were employed because of their pertinence to health care and psychology. Search terms included attitudes, behaviors, screening, evaluation, female sexual health, and female sexual dysfunction. The initial search started broadly with sexual function AND screening which resulted in 23,246 articles. More search terms were added to target the articles being collected. Search combinations included: screening AND female sexual function, screening AND female sexual dysfunction, screening AND attitudes AND female sexual dysfunction, screening AND female sexual health NOT cancer NOT HIV, behaviors AND screening AND female sexual dysfunction, behaviors AND screening AND female sexual health NOT cancer NOT HIV. Articles critiqued for the literature review were from all of the above combinations of searches. More articles utilized the word "sexual dysfunction" rather than "sexual function." Most articles that resulted with the search term sexual health were related to sexually transmitted infections and pregnancy prevention.

Inclusion criteria for articles were those published in peer-reviewed journals from 2005 to 2016, were written in English, and had full text available. The articles needed to assess screening/evaluation attitudes and behaviors in regard to women's sexual health and dysfunction. In an effort to obtain the most effective review of the literature, a librarian at the Dahlgren 
Library of Georgetown University was consulted. The researcher's literature search, and collaboration with the librarian, produced 15 articles which were appraised using Melnyk Model (Appendix D). The Melnyk Model appraises articles based on their level of evidence from one to seven. One being the most rigorous of a randomized control trial to level seven being an expert opinion (Melnyk, \& Fineout-Overholt, 2015). After appraisal it was found that there were 12 level-four studies, two level-five studies and one level-seven expert opinion. The 15 articles were comprised of nine cohort studies, three cross sectional studies, two systematic reviews of the literature, and one expert opinion.

\section{Critique and Synthesis of Previous Evidence}

The 15 articles demonstrated a significant amount of research addressing the importance of screening/evaluating sexual health and the lack of screening. Four of the studies addressed patient perceptions of screening for sexual dysfunction. Eight of the studies addressed provider attitudes of screening for sexual dysfunction. Ten studies used self-administered surveys as their tool for their study. Two articles were a review of the literature themselves. Only one article had a pretest, intervention, and posttest. After reading the articles, there were three themes that emerged: the need to ask patients about sexual health and concerns, the lack of quantity and quality education about female sexual dysfunction, and the perceived lack of time experienced by providers.

The need to ask. According to Papaharitou et al. (2005), "women are reluctant to seek medical advice on their sexual concerns." When women sought care for their complaints, they most often saw an obstetrician/gynecologist or primary care provider (Shifren et al., 2009). Only $6 \%$ of women scheduled an appointment specifically for their sexual health concern. Of those women, $80 \%$ of them initiated the discussion (Shifren et al., 2009). In urogynecology clinics, 
$37 \%$ of women had a sexual complaint but only $17 \%$ initiated the discussion. Therefore, $83 \%$ of patients did not bring up their concerns unless asked specifically (Roos et al., 2012).

Between $73 \%$ and $78 \%$ of patients expect, or prefer, that their provider initiate the discussion, and ask them about their sexual health (Association of Reproductive Health Professionals and the National Women's Health Resource Center, 2009; Shifren et al., 2009). However, in the same study by the Association of Reproductive Health Professionals and the National Women's Health Resource Center (2009), 74\% of providers relied on their patients to initiate a discussion about sexual health. Sobecki, Curlin, Rasinski, and Lindau (2012) found that approximately $63 \%$ of obstetrician/gynecologists routinely asked about patients' sexual activity, and $40 \%$ asked about sexual problems. Of their 1,154 physician participants, less than one third, $28.5 \%$, routinely asked patients about sexual satisfaction, and $27.7 \%$ asked about sexual orientation/identity. Only $13.8 \%$ asked about pleasure or satisfaction with sexual activity. In a study completed by 491 urogynecologists, Goldenhar et al. (2005) reported that most participants considered asking at least one question about sexual activity as evaluation of sexual health.

Adolescents and older populations of women are the least likely to have their sexual health evaluated by their provider. In a study by Alexander et al. (2014), they reported that during annual visits, no adolescents initiated the conversation about sexual health, and two thirds of physicians did not ask adolescents about sex. For those that did, the average conversation was 36 seconds long. In a literature review, Hinchliff and Gott (2011) reported that older people were less likely to seek out medical help for sexual concerns, and that physicians were less likely to ask due to embarrassment or their assumption that sex was less important for older people.

In an effort to better screen patients for sexual dysfunction, questionnaires have been created. The most frequently used validated questionnaire, the Female Sexual Function Index 
(FSFI), uses 19 questions to evaluate six different components of female sexual dysfunction (Rosen et al., 2000). Since it was created, it has been cross-validated for use in multiple languages, for women in adolescents through menopause, pregnant or not, with mixed causes for sexual dysfunction, and for women with chronic medical issues (Rehman, Asif Mahmood, Sheikh, Sultan, \& Khan, 2015). While these questionnaires can make screening for sexual dysfunction more efficient and make asking about sexual health easier, many providers do not utilize them (Kriston, Günzler, Rohde, \& Berner (2010). In an effort to increase screening for sexual dysfunction and to decrease the amount of time patients and providers spent on paperwork, Kriston et al. (2010) created a one-question version as well as a two-question version questionnaire to screen for sexual dysfunction. Their questionnaire had $74 \%$ and $93 \%$ sensitivity and $76 \%$ and $60 \%$ specificity, respectively. While this is promising, questionnaires should not replace the patient-clinician interview and obtaining a sexual history (Kingsberg \& Althof, 2009). Questionnaires can be used as a screener, to minimize time spent with each patient while providing comprehensive assessment, and as an introduction for a conversation about sexual health between the patient and the provider (Kingsberg \& Althof, 2009).

Lack of education. In a literature review completed by Dahir (2009), she noted that not one nursing school in the study had sexual health listed as part of their curriculum. In medical schools, one half of schools had three to ten hours of coursework and was often taught by a psychiatrist. The only requirement in curriculum for teaching sexual dysfunction was from the American Board of Obstetrics and Gynecology for pelvic medicine and reconstructive surgery specialist (Dahir, 2009). Despite this, the membership of the British Society of Urogynecology and the American Urogynecological Society found that $76 \%$ of members thought training in female sexual dysfunction to be unsatisfactory (Roos et al., 2009). 
Kingberg and Knudson (2011) reported, in their review of the literature, that lack of faculty with a focus in sexual health also contributed to the lack of student education regarding sexual health. In a study of medical students, $69 \%$ believe that that sexual concerns will be an important part of their practice, yet only $37 \%$ felt like they were adequately trained to do so. In that same group of students, $57 \%$ felt inadequately trained to take a basic sexual history (Wittenberg \& Gerber, 2009). In a study conducted by Rosen et al. (2006), “48\% of residents indicated that they were uncomfortable with open discussion of sexual issues and would not feel comfortable addressing the topic with their patients." They cited inadequate training, barriers to communication and personal discomfort as reasons. After participating in a half day intensive workshop for sexual health, they reported more comfort with the topic and that they would be more likely to address the sexual issues of their patients (Rosen et al., 2006).

After schooling and residencies, knowledge of female sexual dysfunction remains inadequate. In a study of 1,946 physicians, Bachmann (2009) reported that $60 \%$ of them rated both their knowledge of female sexual dysfunction and comfort level with female sexual dysfunction as poor or fair. Embarrassment about the topic in general, as well as a lack of knowledge on how to address their own embarrassment deterred physicians from screening for, or evaluating patients' sexual dysfunction. Bachman (2009) also found that $86 \%$ of physicians believed that there was a lack of effective treatment options, which may deter them from initiating a conversation or addressing patient concerns if they believe that nothing can be done. Shifren et al. (2009) also found that most women who presented with a sexual problem did not receive any treatment.

Lack of time. In addition to the lack of education, the other most common reason cited for not screening for sexual dysfunction was too little time (Abdolrasulnia et al., 2010, Garcia \& 
Fisher, 2008, Kingsberg \& Knudson, 2011, Roos et al., 2009). According to Sadovsky and Nusbaum (2006) the clinician can "deal with any sexual problem or dysfunction directly, or refer the patient to an appropriately specialized care source." If a provider already does not feel skilled in the topic, it may take them more time to evaluate the patient. Thus if they already feel like they have a lack of time, it can decrease the motivation to screen for sexual dysfunction if their feel inadequately prepared (Garcia \& Fisher, 2008).

\section{Further Research}

In summary, there was not one article that addressed giving health care providers education or resources and the impact on their attitudes and behaviors of screening for sexual dysfunction. From the literature review, no randomized control trials were found. Lack of high quality evidence is likely due to the fact that there is not a significant funding for female sexual dysfunction and it would be difficult to design a randomized control trial for this topic. Since sexual function is so multifactorial, having articles that also assessed psychological concerns and partner support would be helpful to broaden the understanding of sexuality. After their synthesis of the literature, Kingsberg \& Knodson (2011) mentioned that there is a lack of high quality evidence regarding interventions for sexual dysfunction screening and that more high quality research needs to be performed.

\section{Rationale for the Project}

After completing the literature review, it was evident that there is a significant amount of data describing the importance of evaluating for sexual dysfunction and why providers are not evaluating. However, the literature review demonstrated a lack of data of what can be done to increase provider screening of sexual dysfunction within the realm of perceived lack of time. Having this data would allow providers to properly evaluate their patients, acknowledge and 
address their patient concerns without increasing the length of their office visit. As noted in background and literature review, this can increase patient satisfaction, provide improved quality care, fulfill provider's ethical obligations, decrease liability potential and save money within the healthcare system. 


\section{Chapter III: Methods}

\section{Design}

A pre and post-survey study (Appendix E) was completed by healthcare providers at two obstetrics/gynecology practices, and one primary care practice, in the Washington, D.C. area. These departments were targeted because they are where most patients seek assistance with sexual health or dysfunction, according the literature review. It was then requested that participants share the study with colleagues to further increase the sample size and diversity of participants in the study.

\section{Instrument and Tool}

An evidence-based educational video (EBEV) was created, by the DNP student/researcher, based on information found in the review of literature and resources noted below. The video was 15 minutes long, included info-graphic images, and a voice over with explanation of those images. The video included background information on the topic of sexual health, and information that addressed six educational domains. Background information included the definition of sexual health and dysfunction, prevalence of sexual dysfunction, patient's expectations of their providers, reasons providers do not routinely screen, and reassurance to providers that they do not need to know how to solve the patient's concern in that visit. The educational domains included: 1) how to ask about/evaluate a patient's sexual health 2) how to address patients questions/concerns even if the provider did not have a solution that day 3) what a sexual health/medicine specialist is and how to refer to them 4) what a pelvic floor physical therapist is and how to refer to them 5) what a sexuality mental health professional is and how to refer to them and 6) available resources such as websites, organizations, and continuing education opportunities. 
The pre-survey and post-survey were created by the DNP student/researcher, her team, and statistician. It sought to investigate if basic education, and presentation of resources, would increase clinicians' beliefs that they would evaluate a patient's sexual health in the office setting.

The pre-survey included 12 questions. The first five questions collected demographic information which included gender, age range, specialty, licensed/certification, and years in practice. Two questions addressed education of sexual health. The first asked, on a Likert scale of one to ten, what the clinician's training in college or university was in regard to sexual health. The second question, also on a scale from one to ten, asked clinicians how much of their continuing education addressed sexual health. The next five questions of the pre-survey were matched to the same questions in the post-survey in order to evaluate for change after the educational video. These questions were on a Likert scale of one to six to create a forced positive or negative answer. These questions included: How often do you evaluate your patients' sexual health in the ambulatory setting? How comfortable are you with asking/evaluating patients about sexual health and dysfunction in the ambulatory setting? How comfortable are you with addressing patients' questions/concerns about sexual health and dysfunction in the office? What is your understanding of what sexual health experts do, including sexual health/medicine specialist, pelvic floor physical therapist, and sexuality mental health professional, and how to find/refer to them? What is your knowledge of sexual health resources including organizations, websites, and continuing education, for you professionally and for your patients?

The post-survey included 17 questions. The first five questions of the post-survey match the five questions mentioned above from the pre-survey. The word "believe" was added to evaluate their perception that they would change their behavior since it could not actually be measured. 
The next 12 questions of the post-survey were utilized to evaluate how, individually, each of the six educational domains of the video impacted clinicians' perceived future behaviors. These questions were also paired with questions that evaluated the quality of delivery of all six educational domains. This was done to be able to assess the correlation between clinician change and quality of the delivery of the six domain concepts in the video. As mentioned above, the six domains evaluated included: how to ask about/evaluate a patient's sexual health, how to address patients concerns or questions even if the provider did not have a solution that day, what a sexual health/medicine specialist is and how to refer to them, what a pelvic floor physical therapist is and how to refer to them, what a sexuality mental health professional is and how to refer to them, as well as available resources such as websites, organizations, and continuing education opportunities. The questions that addressed the quality of the video were phrased: "The video taught me..." and were ranked on a scale of one to six. One, being "strongly disagree," and six, being "strongly agree." The questions that addressed each domain were phrased: "After viewing the portion of the video that addressed [domain], I am now more likely to evaluate patient's sexual health in the office." These questions were also ranked from one to six, with one being “strongly disagree" and six being "strongly agree." An even Likert-like was chosen to force a positive or negative answer of the participants.

Both the educational intervention and tool were reviewed and approved by academic faculty at Georgetown University, statistician, industry experts and lay people for clarity, content, and feasibility.

\section{Study Objectives}

There were three main objectives for the study. All objectives were evaluated with data from participants who completed the pre-survey, watched the EBEV, and completed the post- 
survey. The first objective was to examine clinician attitudes before and after watching the EBEV. This objective serves to evaluate the EBEV, as a whole, for the potential to create a change in clinicians' attitudes for evaluating patients' sexual health. The second objective was to examine the impact of each of the six educational domains individually. Finally, the third objective was to assess the correlation between the participants quality rating of each domain in the video and impact the on participants' attitudes. Because the researcher created the educational intervention, it was important to examine the participant's perceived quality of coverage of each domain of the video in correlation with their belief that they would be more or less likely to evaluate their patient's sexual health. This was done to explore the possibility of whether the actual information was not effective in creating change, or, that it was due to a poor delivery of the information through the video.

The overall outcome measure was the increased or decreased willingness to evaluate patients' sexual health and dysfunction after participants watched an evidence-based video that addressed background information and information on the six educational domains.

\section{Population}

To recruit participants, an email was sent to nurse practitioners, physician assistants, certified nurse midwives, and physicians in the practices noted above. The email contained a brief description of the project, expectation of how long the survey would take, and the survey link. The email also contained a request to forward the email to colleagues in an effort to create a larger and more diversified sample.

Inclusion criteria: 18years old or older, nurse practitioner, physician assistant, certified nurse midwife, physician, physical therapist, mental health professional, with online internet access 
Exclusion criteria: younger than 18, lack of online access, medical assistant, registered nurse, phlebotomist, administrative staff.

\section{Procedures}

A Gannt chart was created to facilitate a timeline. The IRB application was submitted and subsequently approved. The survey was emailed to contacts in the three practices that agreed to email the survey to their listserv. Data collection took place over a six week period.

\section{Data Analysis Plan}

To meet the study objectives, the data analysis plan was completed with the statistician who was involved in the creation of the survey instrument. Objective one, "examine clinician attitudes before and after watching the evidence-based educational video," was evaluated with questions eight through seventeen. A paired t-test was used to determine the mean difference of change before and after watching the EBEV. Objective two, "examine the impact of each of the six educational domains individually," was evaluated with questions 19, 21, 23, 25, 27 and 29. Descriptive statistics methods including central tendency and percentages were utilized. Objective three, "assess the correlation between the participants quality rating of each domain in the video and impact the on participants' attitudes," was evaluated in two steps. The first was to obtain the ratings of the delivery of information for each domain with questions $18,20,22,24$, 26, and 28. To report this information, descriptive statistics was again utilized for central tendency and percentages. Once the ratings were obtained, to evaluate objective three it was evaluated by pairing questions 18 and 19, 20 and 21, 22 and 23, 24 and 25, 26 and 27, and 28 and 29. A Pearson's correlation coefficient was then run between the pairs of questions. 


\section{Data Management}

This study was completed anonymously by participants through the SurveyMonkey ${ }^{\mathrm{TM}}$ website. The account with the responses was password protected. Only the researcher and statistician had access to the results through the website. The data was downloaded to the statistician's password protected computer and into an excel spreadsheet. The researcher, statistician, and her team were the only people with access to the document. No responses of the survey or any of the data were printed.

\section{Human Subject Review}

The principle investigator and mentor completed the Collaborative Institutional Training Initiative (CITI) program. The project was submitted through the institutional review board (IRB) at Georgetown University in the social and behavioral sciences committee. Informed consent was obtained by all participants through the survey platform. In the survey platform, there was a statement that said "By clicking the link below, I agree to participate."

\section{Project Sponsors and Resources}

There were no project sponsors. The study was self-funded by the DNP student/researcher. Costs incurred included: a) SurveyMonkey ${ }^{\mathrm{TM}}$ account; b) Video producing software; c) Music editing software; d) statistician; e) gift cards for study participants. The total cost to complete the project was estimated at $\$ 1,110.00$ dollars.

Resources included the Georgetown Dahlgren Library, World Health Organization (WHO, Center for Disease Control and Prevention (CDC), International Society for the Study of Women's Sexual Health (ISSWSH), International Society for the Study of Sexual Medicine (ISSM), Sexual Medicine Society of North America (SMSNA), American Association of Sexuality Educators, Counselors and Therapists (AASECT), International Pelvic Pain Society 
(IPPS), International Society for the Study of Vulvovaginal Disorders (ISSVD), Northern American Menopause Society (NAMS), American Society of Reproductive Medicine (ASRM), World Professional for Transgender Health (WPATH), World Association for Sexual Health (WAS), American Physical Therapy Association Section on Women's Health (APTA Section on Women's Health), Society for Sex Therapy and Research (SSTAR), Scientific Study of Sexuality (SSSS), National Vulvodynia Association (NVA), Vulvar Pain Society (VPS). 


\section{Chapter IV: Results}

Data collection and analysis were utilized to evaluate the outcomes' measures of the doctoral project. The three objectives were to examine clinician attitudes before and after watching the evidence-based educational video (EBEV), examine the impact of each of the six educational domains individually, and to assess the correlation between the participants quality rating of each domain in the video and impact the on participants' attitudes. The purpose of chapter four is to present the data and the analysis of the study through statistical methods. In

keeping with most scientific data analysis, the alpha value was set at 0.05 . This means that there was a five percent chance of a type one error, rejecting the null hypothesis when it was actually true. The alpha value was not decreased in an attempt to balance the risk of making a type-one versus type-two error, accepting the null hypothesis when it is not true.

\section{Analysis of Data}

The online survey was sent to three different practices in the Washington, D.C. area, one primary care practice and two OB/GYN practices, which then sent it to their listserv of providers. After, the researcher requested participants send the survey to other professional colleagues to increase the diversity and size of the sample. Data that was collected was sent to a statistician who imported the data into an Excel file. Due to this sampling method and inability to know the number of participants invited, it was not possible to determine the response rate. The method of an online survey was chosen for ease of access to participants and data collection. While the study was anonymous, it is noted that having an online-only survey could create a bias within the sample population, based on who has access to, or chooses to, participate via the internet. 


\section{Characteristics of the Sample}

The survey completion rate was $67.3 \%$. There were 147 participants who completed the pre-survey and 99 participants $(\mathrm{N}=99)$ who also completed the post survey. Those who did not complete the post survey rated themselves more comfortable addressing a patient's sexual health and more likely to screen in the office on the pre-survey. Therefore, those who completed both the pre-survey and post-survey were more likely to rate themselves lower in comfort and practice of evaluating a patient's sexual health during the pre-survey in the demographics section.

Of the 147 pre-survey participants, 146 were female $(99.3 \%)$ and $1(0.7 \%)$ participant skipped the question. The majority of participants' (87.8\%) age range was 25 to 54 years of age. Nurse practitioners or certified nurse midwives comprised $78.23 \%$ of the sample. Approximately $43 \%$ of participants had one to six years of experience. Seventy-five percent of the sample rated their amount of education in university about sexual health as a five or below on a scale of one, no education at all, to ten, very thorough education. Sixty-four percent of the participants rated the amount of continuing education that addressed sexual health that they participated in as five or below on a scale of one, being "none," to ten, being "all of my continuing education addressed sexual health." Table 1 is a summary of the characteristics of the sample that were collected.

Table 1. Characteristics of the Sample

\begin{tabular}{lll}
\hline & $\mathrm{N}$ & $\%$ \\
\hline Gender & & \\
Female & 99 & 100 \\
Male & 0 & 0 \\
Other & 0 & 0 \\
Age & & \\
18 to 24 & 0 & 0 \\
25 to 34 & 29 & 29.29 \\
35 to 44 & 39 & 39.39 \\
45 to 54 & 20 & 20.20 \\
55 to 64 & 11 & 11.11 \\
65 to 74 & 0 & 0 \\
75 or older & 0 & 0
\end{tabular}


Table 1. Characteristics of the Sample (continued)

\begin{tabular}{|c|c|c|}
\hline & $\mathrm{N}$ & $\%$ \\
\hline \multicolumn{3}{|l|}{ Specialty } \\
\hline Obstetrics and Gynecology & 40 & 40.40 \\
\hline Gynecology/Women's Health & 36 & 36.36 \\
\hline Urology & 1 & 1.01 \\
\hline Primary Care/Family Medicine/Internal Medicine/General Practice & 21 & 21.21 \\
\hline Psychology & 1 & 1.01 \\
\hline \multicolumn{3}{|l|}{ Licensed/Certified As } \\
\hline Nurse Practitioner & 55 & 55.56 \\
\hline Certified Nurse Midwife (may also be dual certified NP) & 26 & 26.26 \\
\hline Physician & 4 & 4.04 \\
\hline Physician Assistant & 1 & 1.01 \\
\hline Counselor/Therapist & 1 & 1.01 \\
\hline Physical Therapist & 20 & 20.20 \\
\hline \multicolumn{3}{|l|}{ Years in Practice } \\
\hline 0 & 11 & 11.11 \\
\hline 1 to 3 & 24 & 24.24 \\
\hline 4 to 6 & 19 & 19.19 \\
\hline 7 to 9 & 10 & 10.10 \\
\hline 10 to 15 & 16 & 16.16 \\
\hline 16 to 20 & 11 & 11.11 \\
\hline 25 or more & 8 & 8.08 \\
\hline \multicolumn{3}{|l|}{$\begin{array}{l}\text { On a scale of } 1-10 \text {, in your college/university training, how much education } \\
\text { do you feel you received in regard to sexual health? }\end{array}$} \\
\hline 1: none & 9 & 9.09 \\
\hline 2 & 28 & 27.27 \\
\hline 3 & 12 & 12.12 \\
\hline 4 & 14 & 14.14 \\
\hline 5 & 17 & 17.17 \\
\hline 6 & 6 & 6.06 \\
\hline 7 & 8 & 8.08 \\
\hline 8 & 3 & 3.03 \\
\hline 9 & 0 & 0 \\
\hline 10: very thorough education & 3 & 3.03 \\
\hline \multicolumn{3}{|l|}{$\begin{array}{l}\text { On a scale of } 1 \text { to } 10 \text {, how much continuing education have you participated } \\
\text { in that addresses sexual health? }\end{array}$} \\
\hline 1:none & 20 & 20.20 \\
\hline 2 & 10 & 10.10 \\
\hline 3 & 13 & 13.13 \\
\hline 4 & 11 & 11.11 \\
\hline 5 & 16 & 16.16 \\
\hline 6 & 8 & 8.08 \\
\hline 7 & 9 & 9.09 \\
\hline 8 & 10 & 10.10 \\
\hline 9 & 1 & 1.01 \\
\hline 10: every continuing education opportunity addresses sexual health & 1 & 1.01 \\
\hline
\end{tabular}




\section{Participants' Attitudes Before and After Watching the Video}

There were 147 participants for the pre-survey and 99 participants who completed the post-survey. The mean difference, standard deviation, p-value and t-score were calculated using answers from the 99 respondents who completed both the pre-survey and post-survey. All five pre-survey post-survey questions were on a one to ten Likert scale. The specifics of each question and Likert scale will be discussed below. Because the first three post-survey questions were evaluating clinicians' belief that they would change, the pre-survey questions examined what clinicians actually did in practice and the post-survey questions were formatted to use the same language as the pre-survey questions, but to include the words "believe" or "think" and were in the future tense. The mean difference, standard deviation, $\mathrm{t}$ scores and $\mathrm{p}$-value for the five pre-survey versus post-survey are reported in Tables 2, 3 and 4.

Table 2. Pre-Survey Post-Survey Overall Impact

\begin{tabular}{lllll}
\hline \multicolumn{1}{c}{ Pre-Survey Question } & \multicolumn{1}{c}{ Pre-Survey Question } & $\sigma \overline{\mathrm{x}}$ & $\mathrm{SD}$ & $\mathrm{t}$ \\
\hline $\begin{array}{l}\text { On a scale of } 1 \text { to 10, how often do } \\
\text { you evaluate your patient's sexual } \\
\text { health in the ambulatory setting? }\end{array}$ & $\begin{array}{l}\text { On a scale of 1 to 10, how often } \\
\text { do believe you will evaluate your } \\
\text { patient's sexual health in the } \\
\text { ambulatory setting? }\end{array}$ & & \\
& & & \\
\hline
\end{tabular}


Table 3. Pre-Survey vs. Post-Survey Impact on Comfort

\begin{tabular}{|c|c|c|c|c|}
\hline Pre-Survey Question & Pre-Survey Question & $\sigma \overline{\mathrm{x}}$ & $\mathrm{SD}$ & $\mathrm{t}$ \\
\hline $\begin{array}{l}\text { On a scale of } 1 \text { to } 10 \text {, how } \\
\text { comfortable are you with } \\
\text { asking/evaluating patients about } \\
\text { sexual health and dysfunction in } \\
\text { the ambulatory setting? }\end{array}$ & $\begin{array}{l}\text { On a scale of } 1 \text { to } 10 \text {, how } \\
\text { comfortable do you think you will } \\
\text { be asking/evaluating patients } \\
\text { about sexual health and } \\
\text { dysfunction in the office? }\end{array}$ & 0.93 & 1.99 & 4.64 \\
\hline $\begin{array}{l}\text { On a scale of } 1 \text { to } 10 \text {, how } \\
\text { comfortable are you with } \\
\text { addressing patient } \\
\text { questions/concerns about sexual } \\
\text { health and dysfunction in the } \\
\text { office? }\end{array}$ & $\begin{array}{l}\text { On a scale of } 1 \text { to } 10 \text {, how } \\
\text { comfortable do you think you will } \\
\text { be with addressing patient } \\
\text { questions/concerns about sexual } \\
\text { health and dysfunction in the } \\
\text { office? }\end{array}$ & 0.88 & 1.91 & 4.58 \\
\hline
\end{tabular}

Table 4. Pre-Survey vs. Post-Survey Impact on Knowledge

\begin{tabular}{lllll}
\hline Pre-Survey Question & Pre-Survey Question & $\sigma \overline{\mathrm{x}}$ & $\mathrm{SD}$ & $\mathrm{t}$ \\
\hline $\begin{array}{l}\text { On a scale of } 1 \text { to 10, what is your } \\
\text { understanding of what sexual }\end{array}$ & $\begin{array}{l}\text { On a scale of 1 to 10, what is your } \\
\text { understanding of what sexual }\end{array}$ & & 2.75 & 7.74 \\
health experts (sexual health & health experts (sexual health & & \\
$\begin{array}{l}\text { clinician, pelvic floor physical } \\
\text { therapist, sex counselor/therapist) }\end{array}$ & $\begin{array}{l}\text { clinician, pelvic floor physical } \\
\text { therapist, sex counselor/therapist) }\end{array}$ & & \\
do and how to find/refer to them? & do and how to find/ refer to them? & &
\end{tabular}

On a scale of 1 to 10 , what is your

On a scale of 1 to 10 , what is your 3.07

2.06

14.85

knowledge of sexual health

knowledge of sexual health

resources (organizations, websites,

resources (organizations,

continuing education) for you

websites, continuing education)

professionally and for your

for you professionally and for

patients? your patients?

(Notes: $\mathrm{N}=99 . \sigma \overline{\mathrm{x}}=$ Mean Difference, $\mathrm{SD}=$ Standard Deviation. $\mathrm{t}=\mathrm{t}$ score. $\mathrm{P}$ values for all 5 questions was 0.0001 . Scale for $1^{\text {st }}$ question:1, no understanding, to 10 , excellent understanding. Scale for $2^{\text {nd }}$ question: 1 , not at all knowledgeable, to 10 , knowledgeable)

The first question pair "how often do you evaluate your patient's sexual health in the ambulatory setting" and "how often do believe you will evaluate your patient's sexual health in the ambulatory setting" was on a Likert scale with one being "never" and ten being "always." This pairing was utilized as a general concept of overall change after watching the educational video. The mean difference from pre-test to post test for this question was 3.69 (SD=2.64) 
indicating a statistically significant improvement in clinicians belief that they will evaluate their patient's sexual health.

The next two questions were on a Likert scale from one, not comfortable, to ten, completely comfortable. They evaluated clinician's comfort in asking or evaluating their patient's sexual health and their comfort in addressing patient concerns related to sexual health. The mean difference in clinicians' comfort with asking/evaluating patient's sexual health was $0.93(\mathrm{SD}=1.99)$. The mean difference in clinicians' comfort with addressing their patients questions or concerns was $0.88(\mathrm{SD}=1.91)$. While not as significant a change compared to the questions that addressed overall change or knowledge of resources, an increase in comfort of asking patients about their sexual health, or addressing their concerns or questions, was statistically significant.

The last two questions of the pre-survey post-survey cluster examined clinician's knowledge of resources. These questions utilized a Likert scale from one, no understanding, to ten, excellent understanding. The questions were written exactly the same in the pre-survey as in the post-survey. For the question "what is your understanding of what sexual health experts (sexual health clinician, pelvic floor physical therapist, sex counselor/therapist) do and how to find/refer to them" the mean difference was $1.75(\mathrm{SD}=2.25)$. The mean difference for the question "what is your knowledge of sexual health resources (organizations, websites, continuing education) for you professionally and for your patients?" was 3.07 ( $\mathrm{SD}=2.06)$. It would suggest, that providing participants' with referrals and resources significantly improves the likelihood that they will evaluate their patients' sexual health. 


\section{Evaluation of Participants' Quality Rating of Each Domain}

Given that the researcher created the EBEV, questions were designed to evaluate the video's ability to convey information for each of the six domains. All six questions were on a Likert scale from one to six. With one being "strongly disagree" and with six being "strongly agree." There were 99 participants who completed these questions of the post-survey. The average rating for each of the six questions that began "the video taught me about" was calculated.

Approximately 99\% of participants indicated that they "somewhat agree," "agree" or "strongly agree" that the educational video taught them how to ask patients about their sexual health, and that $83.8 \%$ "somewhat agree," "agree," or "strongly agree" that the video taught them how to address patient's concerns and questions. The participants indicated that $84.8 \%$ of them "somewhat agree" to strongly agree" that the video taught them about sexual health or medicine specialist. Rating "somewhat agree" to "strongly agree," $80.8 \%$ and $82.8 \%$ of participants indicated that the video taught them about pelvic floor physical therapists, and about mental health specialists specializing in sexuality, respectively. Almost 99\% of participants indicated that they "somewhat agree" to "strongly agree" that the video taught them about potentially helpful resources.

Table 5. Evaluation of Participants' Quality Rating of Each Domain

\begin{tabular}{|c|c|c|c|c|c|c|c|c|c|c|c|c|}
\hline \multirow[t]{2}{*}{ The video taught me } & \multicolumn{2}{|c|}{$\begin{array}{l}\text { Strongly } \\
\text { disagree }\end{array}$} & \multicolumn{2}{|c|}{ Disagree } & \multicolumn{2}{|c|}{$\begin{array}{l}\text { Somewhat } \\
\text { disagree }\end{array}$} & \multicolumn{2}{|c|}{$\begin{array}{l}\text { Somewhat } \\
\text { agree }\end{array}$} & \multicolumn{2}{|c|}{ Agree } & \multicolumn{2}{|c|}{$\begin{array}{l}\text { Strongly } \\
\text { agree }\end{array}$} \\
\hline & $\mathrm{N}$ & $\%$ & $\mathrm{~N}$ & $\%$ & $\mathrm{n}$ & $\%$ & $\mathrm{~N}$ & $\%$ & $\mathrm{n}$ & $\%$ & $\mathrm{n}$ & $\%$ \\
\hline How to ask/evaluate & 0 & 0 & 1 & 1.0 & 0 & 0 & 18 & 18.2 & 41 & 41.4 & 39 & 39.4 \\
\hline How to address concerns & 0 & 0 & 1 & 1.0 & 1 & 1.01 & 14 & 14.1 & 45 & 45.4 & 38 & 38.4 \\
\hline ..Sexual health specialist & 0 & 0 & 0 & 0 & 2 & 2.0 & 13 & 13.1 & 55 & 55.6 & 29 & 29.3 \\
\hline ..Pelvic floor PTs & 0 & 0 & 2 & 2.0 & 2 & 2.0 & 15 & 15.1 & 47 & 47.5 & 33 & 33.3 \\
\hline ..Mental health specialists & 0 & 0 & 1 & 1.0 & 1 & 1.0 & 15 & 15.1 & 54 & 54.5 & 28 & 28.3 \\
\hline ..Resources & 0 & 0 & 0 & 0 & 1 & 1.0 & 9 & 9.0 & 41 & 41.4 & 48 & 48.5 \\
\hline
\end{tabular}




\section{Analysis of the Impact of Each Domain}

Six questions in the post survey were created to discern how each educational domain made an impact on the provider's belief that they would evaluate patient's sexual health. The six educational domains were evaluated on a one, strongly disagree, to six, strongly agree Likert scale. A six-point scale was used to force an opinion. These questions were phrased "after viewing portion of the video that addressed [domain], I am now more likely to evaluate patient's sexual health in the office." There were 99 participants who completed this portion of the postsurvey. Descriptive statistics were utilized to evaluate the impact of each domain.

With the education on the domains of "how to ask and evaluate" and "what a sexual medicine specialist does and how to refer to them," $95.9 \%$ of participants chose four, "somewhat agree", to six, "strongly agree," that they were now more likely to evaluate a patient's sexual health. Approximately $97 \%$ of participants chose "somewhat agree" to "strongly agree" for the domain "how to address patient concerns or questions." Now understanding what a pelvic floor physical therapist was and how to refer, $93.9 \%$ of respondents "somewhat agree" to "strongly agree" that they would be more likely to evaluate their patients. With knowledge of sex therapists and how to refer to them, $94.9 \%$ respondents "somewhat agree" to "strongly agree" they were more likely to evaluate patient's sexual health. The educational domain of resources was the most likely to make providers more likely to evaluate their patient's sexual health with approximately $98 \%$ of respondents choosing "somewhat agree" to "strongly agree." 
Table 6. Educational Domain's Impact

\begin{tabular}{|c|c|c|c|c|c|c|c|c|c|c|c|c|}
\hline \multirow[t]{2}{*}{$\begin{array}{l}\text { After viewing the } \\
\text { portion of the video that } \\
\text { addressed__, I am now } \\
\text { more likely to evaluate } \\
\text { patient's sexual health. }\end{array}$} & \multicolumn{2}{|c|}{$\begin{array}{l}\text { Strongly } \\
\text { disagree }\end{array}$} & \multicolumn{2}{|c|}{ Disagree } & \multicolumn{2}{|c|}{$\begin{array}{l}\text { Somewhat } \\
\text { disagree }\end{array}$} & \multicolumn{2}{|c|}{$\begin{array}{l}\text { Somewhat } \\
\text { agree }\end{array}$} & \multicolumn{2}{|c|}{ Agree } & \multicolumn{2}{|c|}{$\begin{array}{l}\text { Strongly } \\
\text { agree }\end{array}$} \\
\hline & $\mathrm{N}$ & $\%$ & $\mathrm{~N}$ & $\%$ & $\mathrm{n}$ & $\%$ & $\mathrm{n}$ & $\%$ & $\mathrm{~N}$ & $\%$ & $\mathrm{n}$ & $\%$ \\
\hline How to ask/evaluate & 0 & 0 & 3 & 3.0 & 1 & 1.0 & 22 & 3 & 38 & 38.4 & 35 & 35.4 \\
\hline How to address concerns & 0 & 0 & 2 & 2.0 & 1 & 1.0 & 22 & 22.2 & 45 & 45.4 & 29 & 29.3 \\
\hline Sexual health specialists & 0 & 0 & 1 & 1.0 & 3 & 3.0 & 21 & 21.2 & 44 & 44.4 & 30 & 30.3 \\
\hline Pelvic floor PTs & 0 & 0 & 3 & 3.0 & 3 & 3.0 & 21 & 21.2 & 43 & 43.4 & 29 & 29.3 \\
\hline Mental health specialists & 0 & 0 & 3 & 3.0 & 2 & 2.0 & 17 & 17.2 & 53 & 53.5 & 24 & 24.2 \\
\hline Reso & 0 & 0 & 2 & 2.0 & 0 & 0 & 20 & 20.2 & 42 & 42.4 & 35 & 35.4 \\
\hline
\end{tabular}

Analysis of Participants' Quality Rating of Each Domain and the Impact on Participant's

\section{Attitudes}

The answers to the six questions that evaluated the educational intervention were then paired with the six questions that evaluated educational domains and their impact. These questions were analyzed by pairing both questions for each domain to discern if there was a negative or positive impact on intent to evaluate a patient's sexual health. "The video taught me about [domain]" was paired to "After viewing portion of the video that addressed [domain], I am now more likely to evaluate patient's sexual health in the office." There were 99 participants who completed the post-survey. A Pearson R correlation was calculated with their responses.

All of the six paired questions had a p-value of 0.0001 . The correlation coefficients for all six questions demonstrated positive correlations and ranged from 0.63 to 0.79 . When respondents rated a portion of the video more highly, they also, on average, were more likely to say that that portion of the video made it more likely that they would address sexual health in the office. 
Table 7. Correlation of Video Quality and Impact on Participants' Attitudes by Domain

The video taught me [domain]

AND

After viewing the portion of the video that addressed [domain], I am now more likely to evaluate a patient's sexual health.

\begin{tabular}{cclrr}
\multicolumn{2}{c}{$\begin{array}{c}\text { Paired } \\
\text { Questions }\end{array}$} & \multicolumn{1}{c}{ Domains } & CC & p-value \\
\hline 18 & 19 & How to ask/evaluate a patient's sexual health & 0.65 & 0.0001 \\
20 & 21 & How to address patient concerns and questions & 0.69 & 0.0001 \\
22 & 23 & About sexual health/medicine specialists and how to find/refer & 0.67 & 0.0001 \\
24 & 25 & About pelvic floor physical therapists and how to find/refer & 0.79 & 0.0001 \\
26 & 27 & About mental health professionals who specialize in sexuality and & 0.72 & 0.0001 \\
& & & \\
28 & 29 & Abow to find/refer & 0.63 & 0.0001 \\
\hline
\end{tabular}

\section{Summary of Findings and Outcomes}

Overall, the EBEV made a statistically significant positive impact on participants. The first objective, examine clinician attitudes before and after watching the EBEV, found that after watching the EBEV, participants will be more likely to evaluate patient's sexual health, feel more comfortable asking about sexual health and addressing patient's questions and concerns, have a better understanding of what sexual health experts do and how to refer to them, and have a better knowledge of resources for sexual health. The second objective, examine the impact of each of the six educational domains individually, found that all domains of education had a positive impact on clinicians. The third objective, assess the correlation between the participants quality rating of each domain in the video and impact the on participants' attitudes, found that the video was ranked highly in all domains. In addition, the higher the domain education in the video was ranked that higher the ranking from the provider that it would change their attitude or behavior.

With 147 pre-survey participants and 99 post-survey participants, $32.7 \%$ of participants did not complete the survey. A possible non-response bias was noted. When the data was 
reviewed, participants who did not complete the survey were more likely rate themselves higher in the pre-survey on their comfort and knowledge of evaluating patient's sexual health.

Therefore, most participants who completed both the pre-survey and post-survey demonstrated a lack of comfort and/or knowledge initially, and had an increase in comfort and/or knowledge after watching the EBEV.

\section{Conclusion}

The EBEV created was satisfactory in addressing the six intended domains of provider education. Each domain had a positive impact for increasing participants' beliefs that they would be more willing to evaluate patient's sexual health. After watching the video, participants indicated that they would feel more comfortable asking patients about their sexual health and addressing their concerns or questions, and had an improved understanding of referral sources and resources in sexual health. All findings were statistically significant. 


\section{Chapter V: Discussion and Conclusion of Findings}

To have a comprehensive understanding of the discussion of findings, it is important to summarize the purpose of this DNP project. Within the literature review, it was found that many women want, and expect, their provider to ask them about their sexual health. However, most providers do not evaluate patients' sexual health due to lack of time, lack of education/training, and/or, lack of knowledge. There is a discrepancy between patients' desires and expectations and providers' behaviors and actions. This means most women are not having their sexual health evaluated or addressed and not receiving comprehensive care. No research articles were found that addressed how to increase provider's evaluation of a patient's sexual health, without increasing the time they spent with the patient, or using their time for additional training on the topic. The purpose of the DNP project was to create an evidence-based educational video about women's sexual health and examine the impact it had on clinicians. There were three objectives to address the gap in clinical practice and in the research. The first objective was to examine clinician attitudes before and after watching the evidence-based educational video (EBEV). The second objective was to examine the impact of each of the six educational domains individually. Finally, the third objective was to assess the correlation between the participants quality rating of each domain in the video and impact the on participants' attitudes.

\section{Participants' Attitudes Before and After Watching the Video}

The results comparing the pre-survey and post-survey were used to evaluate if and how the evidence-based video as a whole made an impact on participants. An increase in the mean difference of 3.69 for the question "after watching the video, on a scale of one to ten, how often do believe you will evaluate your patient's sexual health in the ambulatory setting/office?" demonstrates that the video had a statistically, and thus clinically significant impact overall. In 
this study this was the largest improvement in mean difference. The question was designed to discover if a short evidence-based video can increase clinicians' likelihood to evaluate their patients' sexual health without removing the barriers to evaluation. These barriers, as noted in the literature review, include a lack of time, training, and education or knowledge of the topic of sexual health. These results imply that those who watch the 15 -minute video would increase the likelihood that they will evaluate their patient's sexual health. Utilization of the EBEV could be an efficient and cost effective means to increasing the number of women who have their sexual health evaluated. Thus, producing more comprehensive and fulfilling care.

Comfort in asking patients about their sexual health and in addressing their concerns or questions increased by a mean difference of 0.93 and 0.88 respectively. This denotes that comfort did increase after watching the EBEV. These numbers were statistically significant, but they were the smallest increased in the mean difference of the pre-survey post-survey questions. It should be noted that knowledge, comfort, and increased evaluation of patients' sexual health are not analogous. Knowledge and/or comfort are not necessarily drivers of behavior. Because knowledge increases, it does not always cause comfort to increase. This could potentially explain why there was such a significant overall positive difference after watching the video but a smaller increase in the mean difference in comfort. It would stand to reason that these findings can be applied to the clinical setting. Clinicians may be more likely to evaluate their patients' sexual health due to their increased knowledge from the video but they still may not be comfortable doing it.

Knowledge of sexual health experts and how to refer to them increased a mean difference of 1.75. This statistically significant result can be reassuring in that in less than 15 minutes, clinicians may be able to appropriately refer patients and get them into specialized care sooner. 
Besides the remarkable impact this can make on patients, this benefit has meaningful economic implications as well. Another consideration is the possible benefits for specialized clinicians due to an increase in referrals. With more referrals, they may be able to treat and help more patients. The knowledge of sexual health resources increased by a mean difference of 3.07. This was the second largest increase in the mean difference when comparing the pre-survey and the post survey questions. Again, this statistically significant result is promising because clinicians may now provide their patients with these resources and also use them to improve their clinical knowledge of sexual health. Because most clinicians will not become sexual health experts, it is reassuring to know that a short educational video can significantly improve their knowledge of available resources.

\section{Evaluation of Participants' Quality Rating of Each Domain}

Due to the evidence-based video being created by the researcher, it was important to evaluate the participants' perception of the information delivery for the educational domains. All domains were rated highly by the participants. This demonstrates that in 15 minutes, a significant amount of information regarding sexual health can be delivered in an effective way through a video.

Each of the domains was rated well. This is compelling for future utilization of the EBEV in its entirety, or in as a single domain. For example, if a sex therapist would like to use the portion of the video that addressed what a mental health sexuality specialist was and how to refer to them, they could, knowing that that portion of the video was rated highly. It could be inferred that the increase in belief, that the participant would evaluate their patients' sexual health, was due to the information that they received through the video. Having the rating for each domain was also essential for data analysis, which is further discussed below. 


\section{Analysis of the Impact of Each Domain}

These six questions of the post-survey were evaluate to determine which domains made a positive or negative impact on the provider's belief that they would evaluate patient's sexual health. It was found that all of the domains had a positive impact in increasing the participants' belief that they would evaluate their patients' sexual health. After viewing the portion of the video for each domain, $93.9 \%$ and $98 \%$ of participants said they "somewhat agree" to "strongly agree" that they are now more likely to evaluate their patients' sexual health. This indicates that each domain made clinicians believe they were more likely to evaluate their patients' sexual health, and that each domain may have the same impact if utilized independently. This may encourage sexual health experts to network with other clinicians, knowing that increased knowledge of sexual health experts leads participants to believe that they would be more likely to evaluate their patients' sexual health; thus, producing more referrals to the sexual health experts, and more patients cared for.

The domains that had the highest percentage of participants, $98 \%$ and $97 \%$, "somewhat agree" to "strongly agree" that they would be more likely to evaluate their patients sexual health were "resources", and "how to address patient concerns or questions." The two domains, "how to ask and evaluate," and "resources," were rated as "strongly agree" to increase the likelihood of providers evaluating their patients' sexual health by $35.4 \%$ of participants. This is similar to the results from the t-test of the pre-survey and post-survey in that knowledge of resources increased substantially after the evidence base educational video. It stands to reason that providing clinicians with resources including national websites, organizations, and continuing education opportunities, was the domain of the video that made the most substantial positive impact for clinicians in regard to increasing their likelihood to evaluate patients' sexual health. 


\section{Analysis of Participants' Quality Rating of Each Domain and the Impact on Participant's}

\section{Attitudes}

It was important to examine any correlation between the quality rating of each domain and the participant's belief that they would evaluate their patient's sexual health. One concern was that if the EBEV did a poor job at delivering information for a domain, then participants would have a negative response to their likelihood to evaluate their patients. There was a possibility that the information for each domain could positively impact the participants' likelihood to evaluate their patients' sexual health, but that the result could be negative due to the poor ranking of the domain of the video. All six domains were rated positively in regard to the delivery of the information and for the participants' belief that, with their new knowledge, they would now be more likely to evaluate their patients' sexual health. Through Pearson's correlation coefficient testing, it was found that when respondents rated a portion of the video more highly, they were more likely to say that that portion of the video made it more likely to evaluate their patients' sexual health.

\section{Limitations}

Like many research studies, there were multiple limitations. These included research limitations and logistical limitations. Research limitations include a lack of variety in the sample and biases of participants. While the findings of this study were positive and statistically significant, they should be deciphered in relation to the limitations of this particular study.

Participants for the study were obtained through email, which can inherently bias the sample. It was requested that research participants share the link to the survey to other clinicians who may have been interested in participating in the survey in an effort to broaden and diversify the sample. Because participant's credentials were not validated, it could stand to reason that 
non-clinicians participated in the study. Approximately $78 \%$ of participants were nurse practitioners or certified nurse midwives. The study did not have enough physicians, physical therapists or mental health professionals to discover statistically significant information for each specific group. All participants of the study were female and participating in a study on women's sexual health, which could create more of a willingness to participate and to belief that they will change their practice out of empathy.

Two considerations that could be limitations of the study involve the design of the questions. The first design limitation is that participants self-report their beliefs that they will change in the future and the evaluation of comfort in the pre-survey and post-survey. Participants' post-survey questions were measured on their beliefs rather than on objective data and may not reflect an actual change in practice. Another design limitation was the evaluation of comfort in the pre-survey and post-survey. Because the post-survey questions required participants to consider how they believe they will feel, measuring their perceived future comfort may not be useful or necessary. An increase or decrease in comfort may or may not impact the actions of a healthcare provider. A study that collects objective data, and that has clinicians interacting with patients, would be a more appropriate means to measure the increase or decrease in clinician comfort secondary to watching the EBEV.

There were 147 participants of the pre-test and 99 post-test participants so a non-response bias was considered. Participants who completed the whole study were more likely to rate themselves as less knowledgeable on the pre-survey. Those who chose not to complete the whole study were more likely to rate themselves as more knowledgeable on the pre-survey and may have been the inclination for not completing the survey. The $32.6 \%$ attrition rate may have been related to the length of time for the completion study. 


\section{Implications for Practice}

The study demonstrated that a short EBEV can make a positive difference in providers' beliefs that they will evaluate their patients' sexual health, their comfort in doing so, and their knowledge of resources and referrals. The video can be utilized as it was produced in its entirety. Each domain of the video was rated well so it was able to deliver the information it intended to. The education of each domain made a positive impact on the participant's belief that they would evaluate their patient's sexual health. Therefore, each domain of the video may be viewed separately if needed. Knowing each domain made a positive difference may encourage sexual health specialist, pelvic floor physical therapist, mental health sexuality specialist, and organizations that focus on sexual health, to network with providers. It can be inferred that the more knowledge of referrals and resources a clinician has, the more likely they are to evaluate the patients' sexual health. The domain that consistently made participants of the study most

likely to believe they are more likely to evaluate their patients' sexual health was "resources." To increase the amount of patients who have their sexual health evaluated and addressed, a first action may be as simple as providing students and clinicians a nationally available resource list that they can defer to or share with patients.

\section{Recommendations for Further Study}

This study explored participants' belief that they would be more likely to evaluate their patients' sexual health. Given that there are many factors why providers do not evaluate, a randomized control trial to evaluate if those beliefs become actions in clinical practice would be an appropriate and needed follow-up study.

While all of the domains were rated well by participants, conducting a qualitative study for the domains that scored the lowest, pelvic floor physical therapy and mental health 
professionals specializing in sexuality, to understand where improvements can be made may lead to revisions and improved delivery of content in the evidence-based video. The creation of shorter videos made to address each domain individually could be created through simple editing. Different studies can arise from using these shorter videos. A similar pre-survey postsurvey study could be done for each video to examine if shorter videos may create a change in participants' beliefs or behaviors and if so, which domain made the biggest impact. This data could then be compared to the data from the original EBEV to examine which produces the biggest impact for positive change.

With 147 pre-survey participants, there is a data set that can be statistically evaluated to build upon basic knowledge of clinicians and their characteristics, education, comfort and knowledge of evaluation of sexual health.

\section{Conclusion}

Sexual health is a vital component to medical care and quality of life for patients, however, there is a discrepancy between patient desires and expectations and provider behaviors and actions, which leaves most women not having their sexual health evaluated or addressed. To address this gap in care, the purpose of this study was to create an educational intervention about women's sexual health and examine the impact it had on clinicians. This study was the first to attempt to increase clinician evaluation of women's sexual health without making significant changes to barriers already in place for evaluation: lack of knowledge, training, and time. The objectives of this study were to examine clinician attitudes before and after watching the EBEV, examine the impact of each of the six educational domains individually, and to assess the correlation between the participants quality rating of each domain in the video and impact the on participants' attitudes. 
The 15-minute EBEV was comprised of background information about sexual health and dysfunction, and education on six domains. These domains included how to ask/evaluate sexual health, how to address patient concerns or questions, referral options: sexual medicine specialist, pelvic floor physical therapy, sexuality mental health professionals, and resources: organizations, continuing education and websites.

Results of the pre-survey compared to the post-survey of 99 participants indicated that overall, an EBEV made a positive impact on participants' belief that they would be more likely to evaluate their patients' sexual health. The six domains (how to ask/evaluate sexual health, how to address patient concerns or questions, referral options: sexual medicine specialist, pelvic floor physical therapy, sexuality mental health professionals, and resources: organizations, continuing education and websites) were each rated highly in their delivery of content through the video and for their likelihood that participants believed they would be more likely to evaluate their patients' sexual health after obtaining that knowledge. There was a correlation with how well the domain of the video was rated by participants and with the participants increased likelihood they believed they would evaluate their patients.

In conclusion, a short EBEV could make a difference in provider evaluation of patient sexual health. Having clinicians watch a 15-minute video that comprises information on the background of sexual health, how to ask/evaluate sexual health, how to address patient concerns or questions, referral options, and resources, was statistically significant for clinicians believing they would be more likely to evaluate their patients' sexual health. Future studies are needed to examine if these beliefs translate into action and to continue to explore the impact education has on clinicians. 


\section{Appendix A: Iowa Model for Evidence-Based Practice}

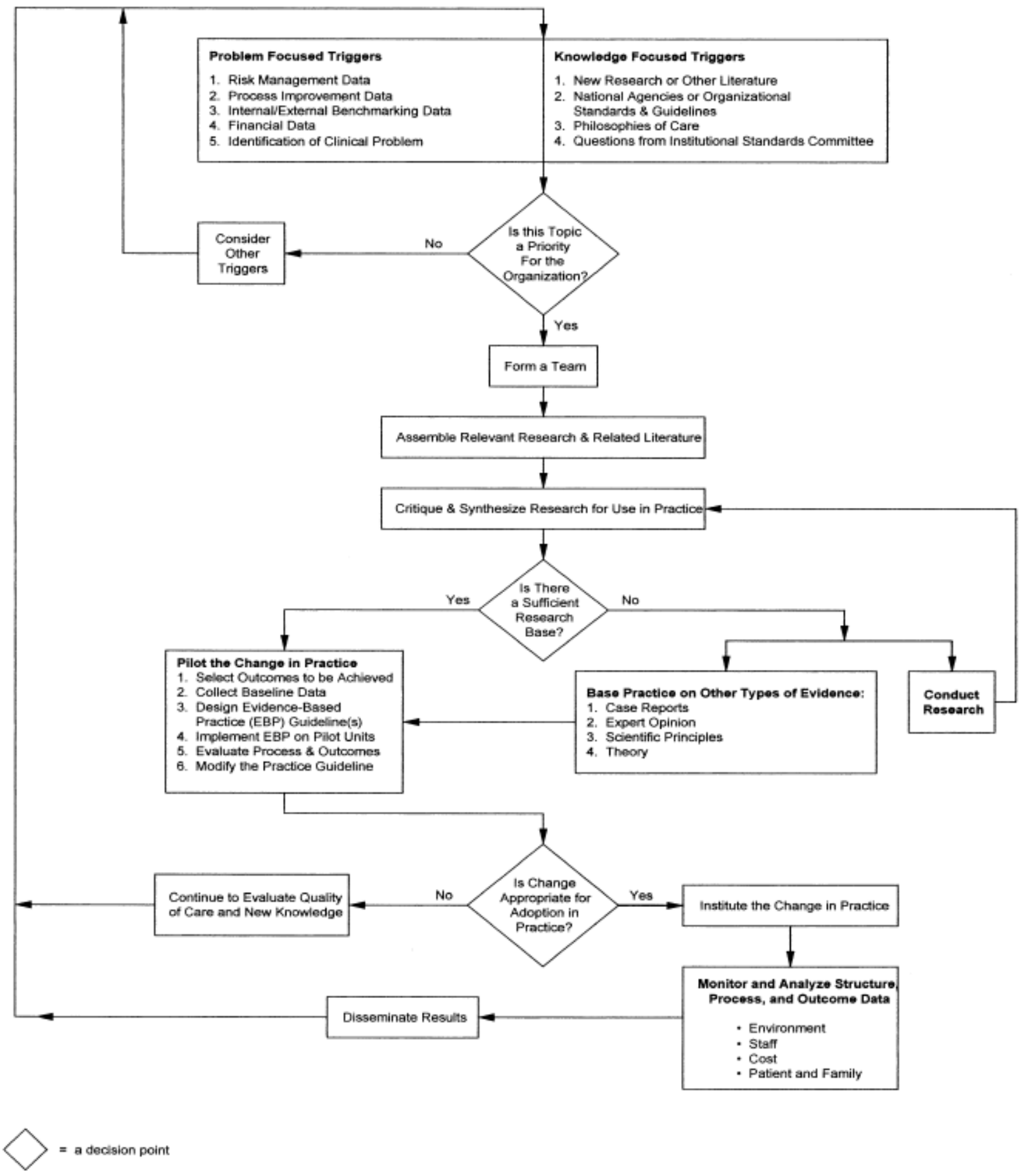

(Source: Titler et al. (2001) 


\section{Appendix B: Non-Linear Model of Female Sexual Response}

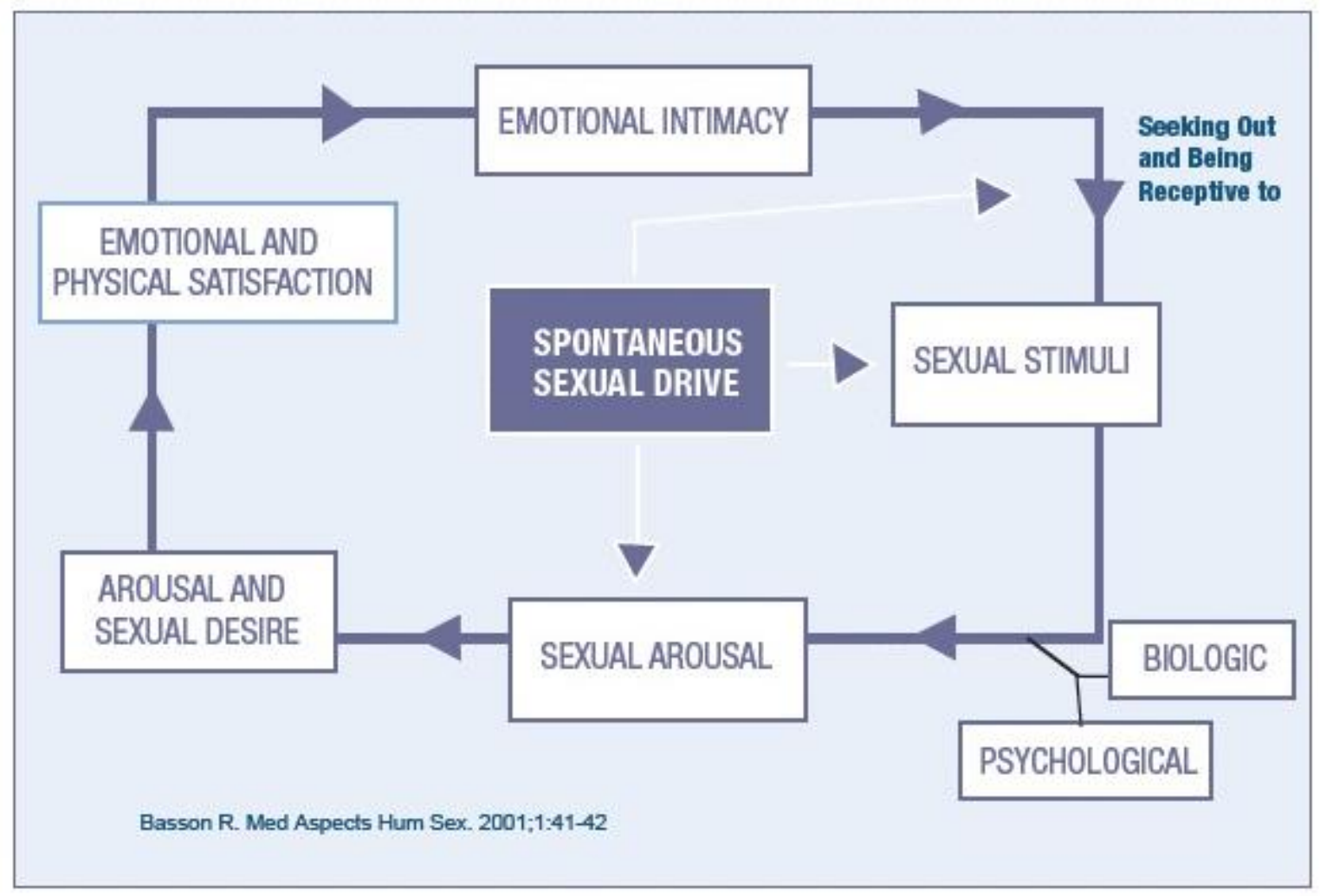

(Source: Association of Reproductive Health Professionals, n.d.) 


\section{Appendix C: Adult Learning Theory}

\section{KNOWLES' \\ 5 ASSUMPTIONS OF ADULT LEARNERS}

In 1980, Knowles made 4 assumptions about the characteristics of adult learners (andragogy) that are different from the assumptions about the characteristics of child learners (pedagogy). In 1984, Knowles added the 5th assumption.

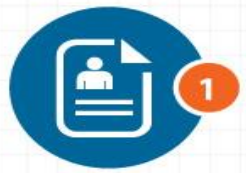

SELF-CONCEPT

As a person matures his/her self concept moves from one of being a dependent personality toward one of being a self-directed human being

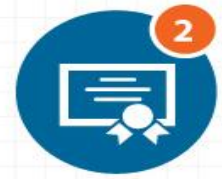

ADULT LEARNER EXPERIENCE

As a person matures he/she accumulates a growing reservoir of experience that becomes an increasing resource for learning.

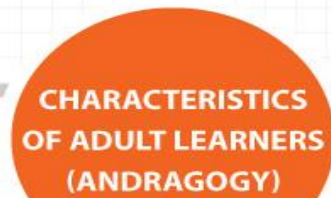

(ANDRAGOGY)

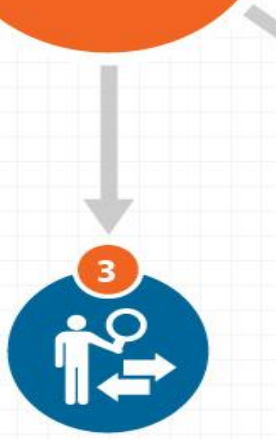

READINESS TO LEARN

As a person matures his/her readiness to learn becomes oriented increasingly to the developmental tasks of his/her social roles.

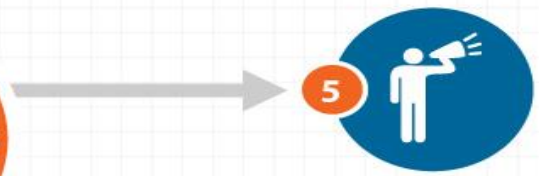

MOTIVATION TO LEARN As a person matures the motivation to learn is internal (Knowles 1984:12).

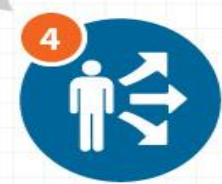

ORIENTATION TO LEARNING As a person matures his/her time perspective changes from one of postponed application of knowledge

to immediacy of application, and accordingly his/her orientation toward learning shifts from one of subject-centeredness to one of problem centeredness.

\section{KNOWLES'}

\section{PRINCIPLES OF ANDRAGOGY}

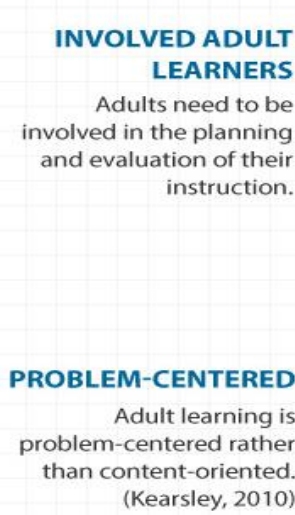

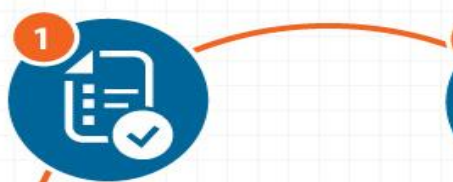

In 1984 ,

Knowles suggested

4 principles that are applied to adult learning:

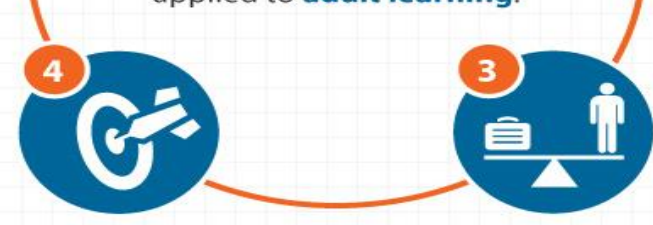

ADULT LEARNERS' EXPERIENCE

Experience (including mistakes) provides the basis for the learning activities.

RELEVANCE \& IMPACT TO LEARNERS' LIVES

Adults are most interested in learning subjects that have immediate relevance and impact to their job or personal life.

(Source: Pappas, C. 2013) 


\section{Appendix D: Melnyk Levels of Evidence}

Level I: Evidence from a systematic review of all relevant randomized controlled trials (RCT's), or evidence-based clinical practice guidelines based on systematic reviews of RCT's

Level II: Evidence obtained from at least one well-designed Randomized Controlled Trial (RCT)

Level III: Evidence obtained from well-designed controlled trials without randomization, quasi-experimental

Level IV: Evidence from well-designed case-control and cohort studies

Level V: Evidence from systematic reviews of descriptive and qualitative studies

Level VI: Evidence from a single descriptive or qualitative study

Level VII: Evidence from the opinion of authorities and/or reports of expert committees

(Source: East Carolina University. (2018) 


\section{Appendix E: Pre and Post Survey}

\begin{tabular}{|c|c|c|c|c|}
\hline \multirow{2}{*}{$\begin{array}{l}\# \\
1\end{array}$} & \multicolumn{2}{|l|}{ Pre Survey } & \# & Post Survey \\
\hline & Gender: & $\begin{array}{l}\text { Male } \\
\text { Female } \\
\text { Other }\end{array}$ & & \\
\hline 2 & Age: & & & \\
\hline 3 & Specialty: & $\begin{array}{l}\text { Obstetrics and Gynecology } \\
\text { Gynecology/Women's } \\
\text { Health } \\
\text { Urology } \\
\text { Primary Care/Family } \\
\text { Medicine/Internal } \\
\text { Medicine/General Practice } \\
\text { Psychology } \\
\text { Other }\end{array}$ & & \\
\hline 4 & $\begin{array}{l}\text { Licensed/Ce } \\
\text { applicable) }\end{array}$ & $\begin{array}{l}\text { ified as: (choose all } \\
\text { Nurse Practitioner } \\
\text { Certified Nurse Midwife } \\
\text { Physician Assistant } \\
\text { Physician } \\
\text { Counselor/Therapist } \\
\text { Physical Therapist } \\
\text { Other: }\end{array}$ & & \\
\hline 5 & Years in Pra & ice: & & \\
\hline 6 & $\begin{array}{c}\text { On a scale c } \\
\text { college/univ } \\
\text { education d } \\
\text { regard to se } \\
0 \\
0 \\
0 \\
0 \\
0 \\
0 \\
0 \\
0 \\
0 \\
0 \\
0 \\
0 \\
\end{array}$ & $\begin{array}{l}1 \text { to } 10 \text {, in your } \\
\text { sity training, how much } \\
\text { you feel you received in } \\
\text { al health? } \\
\text { None } \\
\text {-Very thorough education }\end{array}$ & & \\
\hline 7 & $\begin{array}{l}\text { On a scale c } \\
\text { continuing } \\
\text { in that addr } \\
0\end{array}$ & $\begin{array}{l}1 \text { to } 10 \text {, how much } \\
\text { ucation have you participated } \\
\text { ses sexual health? } \\
\text { None }\end{array}$ & & \\
\hline
\end{tabular}




\begin{tabular}{|c|c|c|c|c|}
\hline & $\begin{array}{ll}\circ & 2 \\
\circ & 3 \\
\circ & 4 \\
\circ & 5 \\
\circ & 6 \\
\circ & 7 \\
\circ & 8 \\
\circ & 9 \\
& 1 \\
& \mathrm{e} \\
& \text { St }\end{array}$ & $\begin{array}{l}\text { Every continuing } \\
\text { lucation opportunity addresses } \\
\text { xual health }\end{array}$ & & \\
\hline 8 & $\begin{array}{r}\text { On a scale } \mathrm{o} \\
\text { evaluate you } \\
\text { ambulatory } \\
0 \\
0 \\
0 \\
0 \\
0 \\
0 \\
0 \\
0 \\
0 \\
0\end{array}$ & $\begin{array}{l}1 \text { to } 10 \text {, how often do you } \\
\text { patient's sexual health in the } \\
\text { etting? } \\
1 \text {-- never } \\
2 \\
3 \\
4 \\
5 \\
6 \\
7 \\
8 \\
9 \\
10 \text {-always }\end{array}$ & 13 & $\begin{array}{l}\text { On a scale of } 1 \text { to } 10 \text {, how often do } \\
\text { believe you will evaluate your patient's } \\
\text { sexual health in the ambulatory setting? } \\
\qquad \begin{array}{cl}\circ & 1 \text {--never } \\
\circ & 2 \\
\circ & 3 \\
\circ & 4 \\
\circ & 5 \\
\circ & 6 \\
\circ & 7 \\
\circ & 8 \\
\circ & 9 \\
\circ & 10 \text { - every time }\end{array}\end{array}$ \\
\hline 9 & $\begin{array}{r}\text { On a scale o } \\
\text { you with ask } \\
\text { sexual health } \\
\text { ambulatory } \\
\\
0 \\
\\
\circ \\
\circ \\
\circ \\
\circ \\
\end{array}$ & $\begin{array}{l}1 \text { to } 10 \text {, how comfortable are } \\
\text { ing/evaluating patients about } \\
\text { and dysfunction in the } \\
\text { etting? } \\
1-\text { not comfortable } \\
2 \\
3 \\
4 \\
5 \\
6 \\
7 \\
8 \\
9 \\
10 \text {-completely } \\
\text { comfortable }\end{array}$ & 14 & 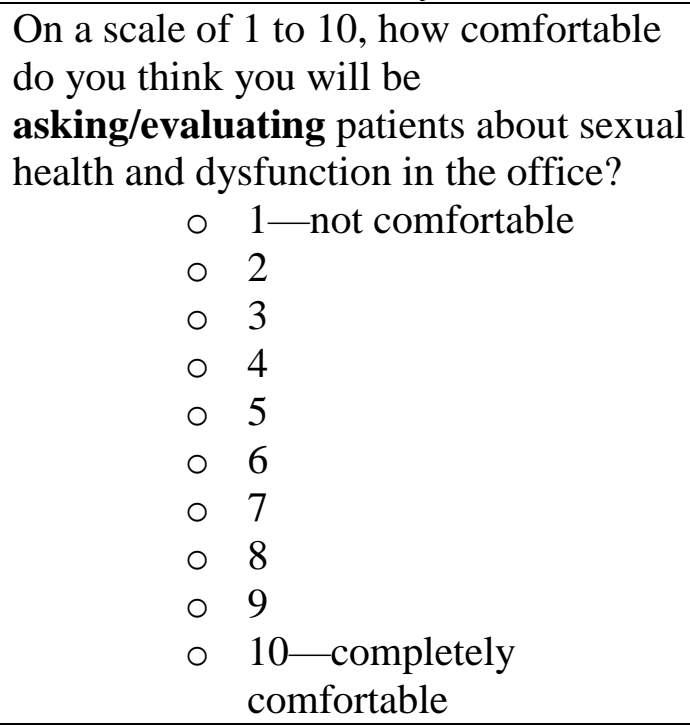 \\
\hline 10 & $\begin{array}{r}\text { On a scale o } \\
\text { you with ad } \\
\text { questions/co } \\
\text { dysfunction } \\
0 \\
0 \\
0\end{array}$ & $\begin{array}{l}1 \text { to } 10, \text { how comfortable are } \\
\text { ressing patient } \\
\text { cerns about sexual health and } \\
\text { n the office? } \\
1-\text { not comfortable } \\
2 \\
3\end{array}$ & 15 & $\begin{array}{l}\text { On a scale of } 1 \text { to } 10 \text {, how comfortable } \\
\text { do you think you will be with } \\
\text { addressing patient questions/concerns } \\
\text { about sexual health and dysfunction in } \\
\text { the office? } \\
\qquad \begin{aligned} \circ & 1-\text { not comfortable } \\
\circ & 2\end{aligned}\end{array}$ \\
\hline
\end{tabular}




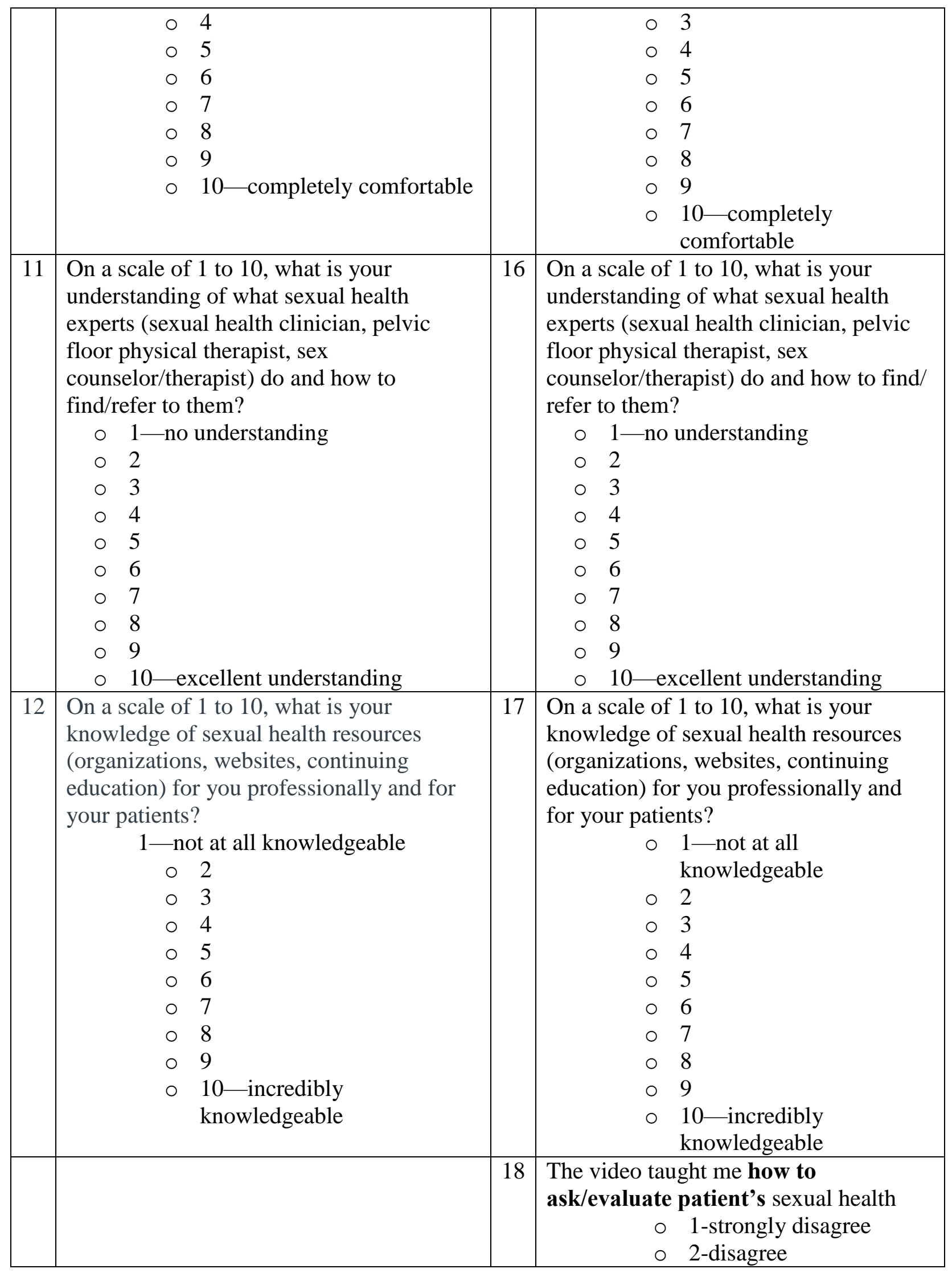




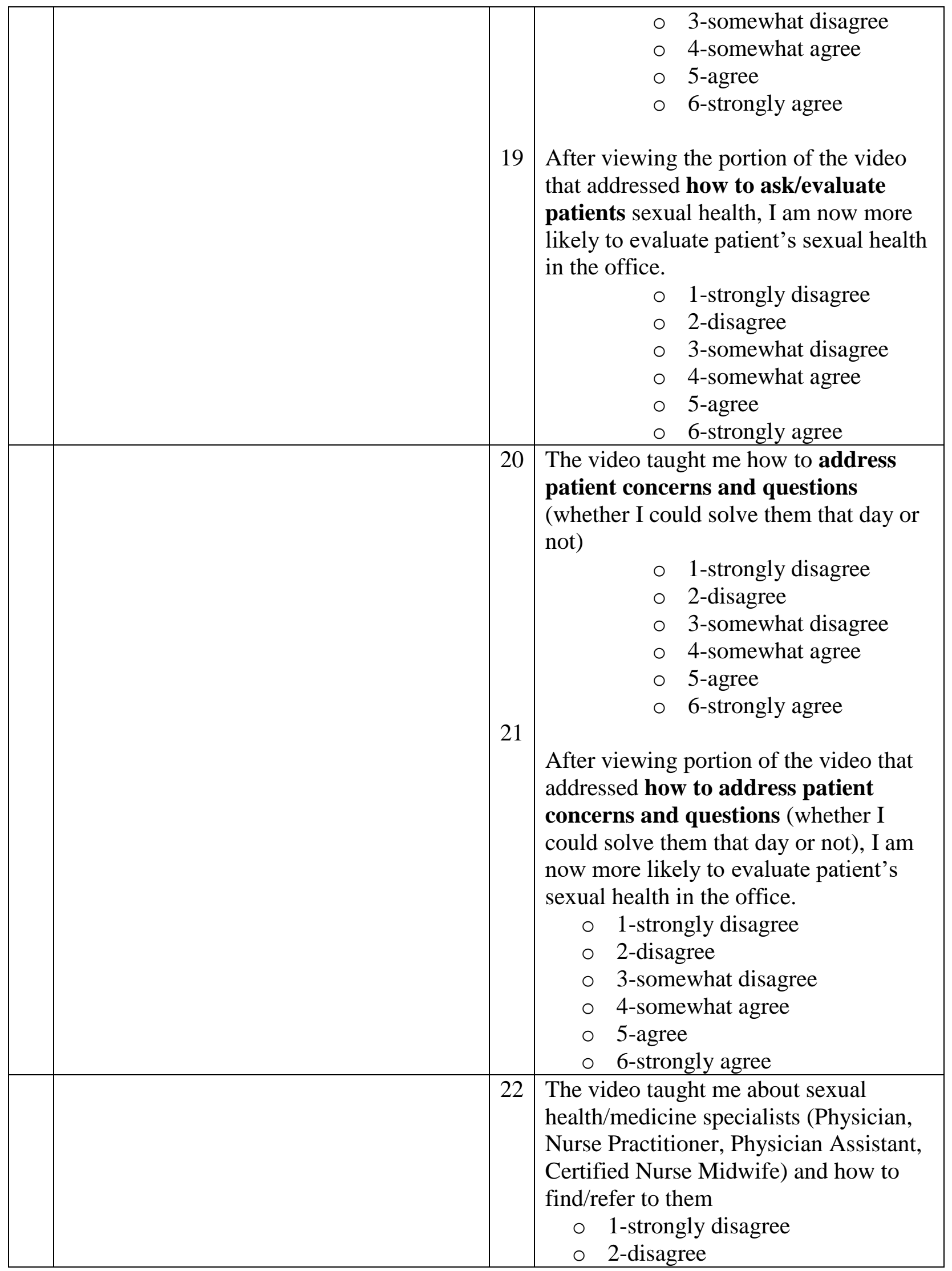




\begin{tabular}{|c|c|c|c|}
\hline & & 23 & $\begin{array}{ll} & \text { 3-somewhat disagree } \\
\circ & \text { 4-somewhat agree } \\
\circ & \text { 5-agree } \\
\circ & \text { 6-strongly agree } \\
& \\
\text { After viewing portion of the video that } \\
\text { addressed sexual health/medicine } \\
\text { specialists (Physician, Nurse } \\
\text { Practitioner, Physician Assistant, } \\
\text { Certified Nurse Midwife) and how to } \\
\text { find/refer to them, I am now more likely } \\
\text { to evaluate patient's sexual health in the } \\
\text { office. } \\
\circ \text { 1-strongly disagree } \\
\circ \text { 2-disagree } \\
\circ \text { 3-somewhat disagree } \\
\circ \text { 4-somewhat agree } \\
\circ \text { 5-agree } \\
\circ \text { 6-strongly agree }\end{array}$ \\
\hline & & 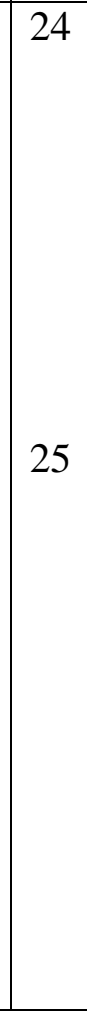 & $\begin{array}{l}\text { The video taught me about pelvic floor } \\
\text { physical therapists and how to } \\
\text { find/refer to them } \\
\circ \text { 1-strongly disagree } \\
\circ \text { 2-disagree } \\
\circ \text { 3-somewhat disagree } \\
\circ \text { 4-somewhat agree } \\
\circ \text { 5-agree } \\
\circ \text { 6-strongly agree } \\
\text { After viewing portion of the video that } \\
\text { addressed pelvic floor physical } \\
\text { therapist and how to find/refer to them, } \\
\text { I am now more likely to evaluate } \\
\text { patient's sexual health in the office. } \\
\circ \text { 1-strongly disagree } \\
\circ \text { 2-disagree } \\
\circ \text { 3-somewhat disagree } \\
\circ \text { 4-somewhat agree } \\
\circ \text { 5-agree } \\
\circ \text { 6-strongly agree }\end{array}$ \\
\hline & & 26 & $\begin{array}{l}\text { The video taught me about mental } \\
\text { health professionals who specialize in } \\
\text { sexuality and how to find/refer to them } \\
\circ \text { 1-strongly disagree } \\
\circ \text { 2-disagree } \\
\circ \text { 3-somewhat disagree }\end{array}$ \\
\hline
\end{tabular}




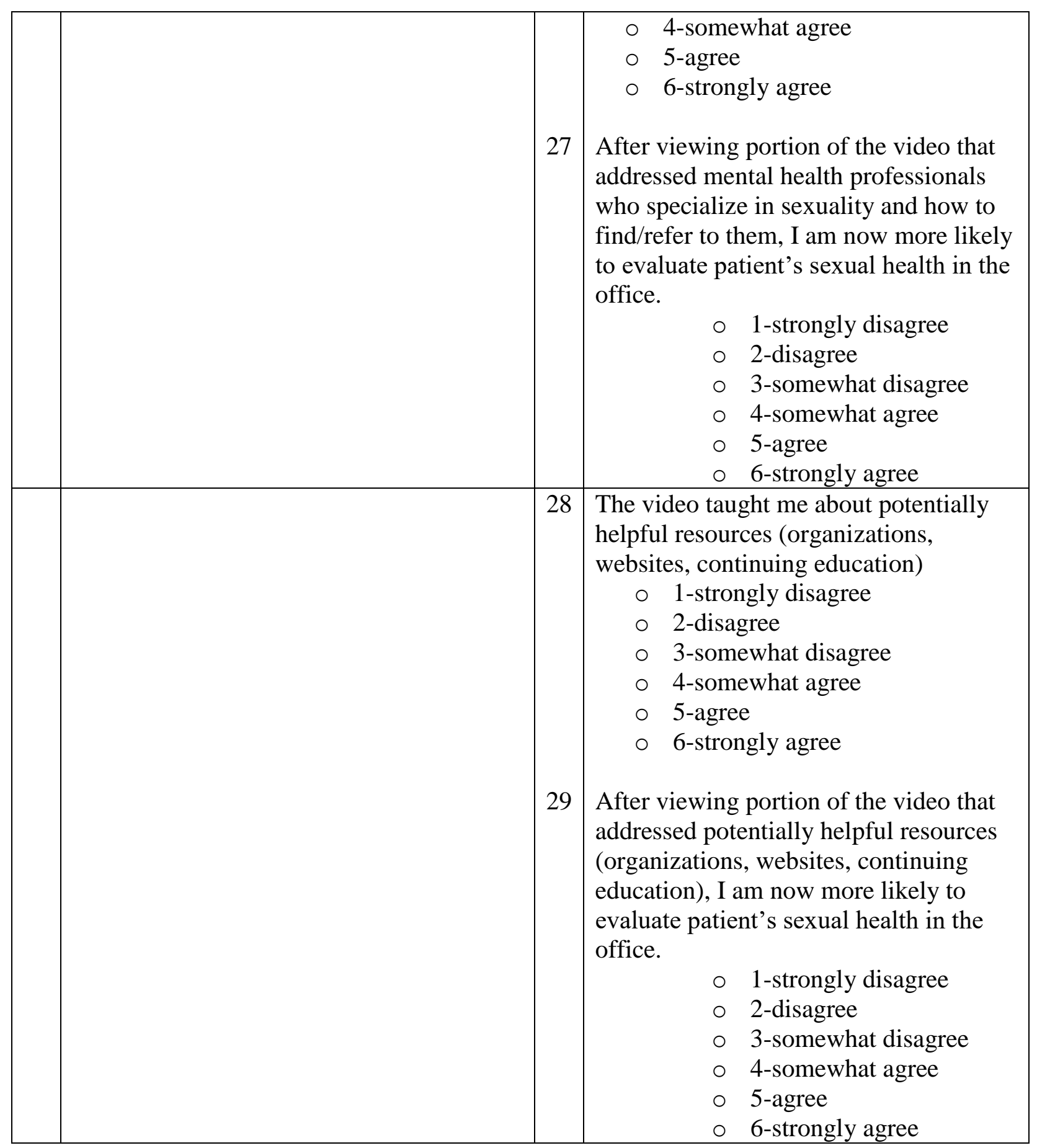




\section{References}

Abdolrasulnia, M., Shewchuk, R. M., Roepke, N., Granstaff, U. S., Dean, J., Foster, J., ... Casebeer, L. (2010). Management of female sexual problems: Perceived barriers, practice patterns, and confidence among primary care physicians and gynecologists. The Journal of Sexual Medicine, 7(7), 2499-2508.

Alexander, S., Fortenberry, J., Pollak, K., Bravender,T., Davis, J., Ostbye, T., ...Shields, C. G. (2014). Sexuality talk during adolescent health maintenance visits. Journal of the American Medical Association (JAMA) Pediatrics, 168(2), 163-169.

American Sexual Health Association (n.d.) JAMA Viewpoint on Sexual Health in America. Retrieved from http://www.ashasexualhealth.org/jama-viewpoint-sexual-health-america/

Association of Reproductive Health Professionals. (n.d.). Handbook On Female Sexual Health And Wellness. Retrieved from http://www.arhp.org/Publications-and-Resources/ClinicalPractice-Tools/Handbook-On-Female-Sexual-Health-And-Wellness/Female-SexualResponse

Association of Reproductive Health Professionals and the National Women's Health Resource Center. (2009). Women's Sexual Health: Provider Survey. Retrieved from www.arhp.org/Publications-and-Resources/Studiesand-Surveys/SHY-Survey

Attitude. (n.d). In Merriam Webster Dictionary online. Retrieved from http://www.merriamwebster.com/dictionary/attitude

Bachmann, G. (2006). Female sexuality and sexual dysfunction: Are we stuck on the learning curve? The Journal of Sexual Medicine, 3(4), 639-645.

Basson, R. (2001). Human sex-response cycles. Journal of Sex and Martial Therapy, 27(1), 3343.

Basson, R., Leiblum, S., Brotto, L., Derogatis, L., Fourcroy, J., Fugl-Meyer, K., ... Schultz. (2004). Revised definitions of women's sexual dysfunction. Journal of Sexual Medicine, $1(1), 40-48$

Behavior. (n.d). In Merriam Webster Dictionary online. Retrieved from http://www.merriamwebster.com/dictionary/behaviors

Bornstein, J., Goldstein, A., Stockdale, C., Bergeron, S., Pukall, C., Zolnoun, D., \& Coady, D. (2016). 2015 ISSVD, ISSWSH, and IPPS consensus terminology and classification of persistent vulvar pain and vulvodynia. The Journal of Sexual Medicine, 13(4), 607-612.

Cardoso, C., Ellenbogen, M. A., Serravalle, L., \& Linnen, A. M. (2013). Stress-induced negative mood moderates the relation between oxytocin administration and trust: evidence for the tend-and-befriend response to stress? Psychoneuroendocrinology, 38(11), 2800-2804.

Clayton, A. H., \& Groth, J. (2013). Etiology of female sexual dysfunction. Women's Health, 9(2), 135-137.

Collett, B., Cordle, C., Stewart, C., \& Jagger, C. (1998). A comparative study of women with chronic pelvic pain, chronic nonpelvic pain and those with no history of pain attending general practitioners. BJOG: An International Journal of Obstetrics \& Gynaecology, 105(1), 87-92.

Dahir, M. (2009). Female sexual dysfunction: barriers to treatment. Urologic Nursing, 29(2), 81.

East Carolina University. 2018. Evidence-Based Practice for Nursing: Evaluating the Evidence. Retrieved from http://libguides.ecu.edu/c.php?g=17486\&p=97640

Edelstein, L. (1943). The Hippocratic Oath, text, translation and interpretation. Baltimore: The Johns Hopkins press. 
Ellison, C.R. (2000). Women's Sexualities. Generations of Women Share Intimate Secrets of Sexual Self-Acceptance. Oakland, CA: New Harbinger.

Evaluate. (n.d). In Merriam Webster Dictionary online. Retrieved from

Garcia, M., \& Fisher, W. A. (2008). Obstetrics and gynaecology residents' self-rated knowledge, motivation, skill, and practice patterns in counselling for contraception, STI prevention, sexual dysfunction, and intimate partner violence and sexual coercion. Journal of Obstetrics and Gynaecology Canada, 30(1), 59-66.

Goldenhar, L., Karram, M., Kleeman, S., Pauls, R., Segal, J., \& Silva, W. (2005). Practice patterns of physician members of the American Urogynecologic Society regarding female sexual dysfunction: Results of a national survey. International Urogynecology Journal, 16(6), 460-467

Grewen, K. M., \& Light, K. C. (2011). Plasma oxytocin is related to lower cardiovascular and sympathetic reactivity to stress. Biological Psychology, 87(3), 340-349.

Healthy People 2020. (n.d.) Reproductive and Sexual Health. Retrieved from https://www.healthypeople.gov/2020/leading-health-indicators/2020-lhitopics/Reproductive-and-Sexual-Health

Hinchliff, S., \& Gott, M. (2011). Seeking medical help for sexual concerns in mid-and later life: a review of the literature. Journal of Sex Research, 48(2-3), 106-117.

Jena, A. B., Seabury, S., Lakdawalla, D., \& Chandra, A. (2011). Malpractice risk according to physician specialty. New England Journal of Medicine, 365(7), 629-636.

Kaplan, H. S. (1977). Hypoactive sexual desire. Journal of Sex \& Marital Therapy, 3(1), 3-9.

Khajehei, M., Doherty, M., Tilley, P. J., \& Sauer, K. (2015). Prevalence and risk factors of sexual dysfunction in postpartum Australian women. The Journal of Sexual Medicine, 12(6), 1415-1426.

Kingsberg, S., \& Althof, S. E. (2009). Evaluation and treatment of female sexual disorders. International Urogynecology Journal, 20(1), 33-43.

Kingsberg, S. A., \& Knudson, G. (2011). Female sexual disorders: Assessment, diagnosis, and treatment. CNS Spectrums, 16(2), 49-62.

Knowles, M. S. (1984). Andragogy in action: Applying modern principles of adult education. San Francisco: Jossey-Bass.

Kriston, L., Günzler, C., Rohde, A., \& Berner, M. M. (2010). Is one question enough to detect female sexual dysfunctions? A diagnostic accuracy study in 6,194 women. The Journal of Sexual Medicine, 7(5), 1831-1841.

Mathias, S., Kuppermann, M., Liberman, R., Lipschutz, R., \& Steege, J. (1996). Chronic pelvic pain: prevalence, health-related quality of life, and economic correlates. Obstetrics \& Gynecology, 87(3), 321-327.

Melnyk, B.M., \& Fineout-Overholt, E., (2015). Evidence-based practice in nursing and healthcare: a guide to best practice. Third edition. Philadelphia: Wolters Kluwer.

Nusbaum, M. R., Gamble, G., Skinner, B., \& Heiman, J. (2000). The high prevalence of sexual concerns among women seeking routine gynecological care. Journal of Family practice, 49(3), 229

Papaharitou, S., Nakopoulou, E., Kirana, P., Iraklidou, M., Athanasiadis, L., \& Hatzichristou, D. (2005). Women's sexual concerns: Data analysis from a help-line. The Journal of Sexual Medicine, 2(5), 652-657. 
Pappas, C. (2013). The Adult Learning Theory - Andragogy - of Malcolm Knowles. Retrieved from https://elearningindustry.com/the-adult-learning-theory-andragogy-of-malcolmknowles

Rehman, K. U., Asif Mahmood, M., Sheikh, S. S., Sultan, T., \& Khan, M. A. (2015). The Female Sexual Function Index (FSFI): Translation, Validation, and Cross-Cultural Adaptation of an Urdu Version "FSFI-U”. Sexual Medicine, 3(4), 244-250.

Roos, A. M., Sultan, A. H., \& Thakar, R. (2012). Sexual problems in the gynecology clinic: are we making a mountain out of a molehill? International Urogynecology Journal, 23(2), $145-152$.

Roos, A. M., Thakar, R., Sultan, A. H., \& Scheer, I. (2009). Female sexual dysfunction: are urogynecologists ready for it? International Urogynecology Journal, 20(1), 89-101.

Rosen, C. Brown, J. Heiman, S. Leiblum, C. Meston, R. Shabsigh,... R. D'Agostino, R. (2000). The Female Sexual Function Index (FSFI): a multidimensional self-report instrument for the assessment of female sexual function. Journal of Sex \&Marital Therapy, 26(2), 191208.

Rosen, R., Kountz, D., Post-Zwicker, T., Leiblum, S., \& Wiegel, M. (2006). Original ResearchEducation: Sexual Communication Skills in Residency Training: The Robert Wood Johnson Model. The Journal of Sexual Medicine, 3(1), 37-46.

Sadovsky, R., \& Nusbaum, M. (2006). Reviews: sexual health inquiry and support is a primary care priority. The Journal of Sexual Medicine, 3(1), 3-11.

Satcher, D., Hook, E. W., \& Coleman, E. (2015). Sexual health in America: improving patient care and public health. Journal of the American Medical Association (JAMA), 314(8), $765-766$.

Schein, E. (2010). Organizational culture and leadership. Hoboken: John Wiley \& Sons.

Shifren, J. L., Johannes, C. B., Monz, B. U., Russo, P. A., Bennett, L., \& Rosen, R. (2009). Helpseeking behavior of women with self-reported distressing sexual problems. Journal of Women's Health, 18(4), 461-468.

Shifren, J. L., Monz, B. U., Russo, P. A., Segreti, A., \& Johannes, C. B. (2008). Sexual problems and distress in United States women: prevalence and correlates. Obstetrics \& Gynecology, 112(5), 970-978.

Simoens, S., Dunselman, G., Dirksen, C., Hummelshoj, L., Bokor, A., Brandes, ... \& D'Hooghe, T. (2012). The burden of endometriosis: costs and quality of life of women with endometriosis and treated in referral centres. Human Reproduction, 27(5), 1292-1299.

Sobecki, J. N., Curlin, F. A., Rasinski, K. A., \& Lindau, S. T. (2012). What we don't talk about when we don't talk about sex: results of a national survey of US obstetrician/ gynecologists. The Journal of Sexual Medicine, 9(5), 1285-1294.

Swartzendruber, A., \& Zenilman, J. M. (2010). A national strategy to improve sexual health. The Journal of the American Medical Association (JAMA), 304(9), 1005-1006.

Teaching Excellence in Adult Literacy. 2011. TEAL Center Fact Sheet No. 11: Adult Learning Theories.

Titler, M., Kleiber, C., Steelman, V., Rakel, B., Budreau, G., Everett, L., ... Goode, C. J. (2001). The Iowa Model of evidence-based practice to promote quality care. Critical Care Nursing Clinics of North America, 13(4), 497-509.

University of California San Fransisco (UCSF) School of Medicine. (2008). Autonomy vs. Beneficence. Retrieved from http://missinglink.ucsf.edu/lm/ethics/Content\%20Pages/ fast_fact_auton_bene.htm 
Welch, M., Margolis, K., Li, Z., \& Gershon, M. (2014). Oxytocin regulates gastrointestinal motility, inflammation, macromolecular permeability, and mucosal maintenance in mice. American Journal of Physiology-Gastrointestinal and Liver Physiology, 307(8), G848G862

Whipple, B., Knowles, J., Davis, J., Gianotten, W., \& Owens, A. (2007). The health benefits of sexual expression. Sexual health, 1(1), 17-42.

Whipple, B., \& Komisaruk, B. R. (1988). Analgesia produced in women by genital selfstimulation. Journal of Sex Research, 24(1), 130-140.

Williams, K., \& Reynolds, M. F. (2006). Sexual dysfunction in major depression. CNS Spectrums, 11(S9), 19-23.

Wittenberg, A., \& Gerber, J. (2009). Recommendations for improving sexual health curricula in medical schools: results from a two-arm study collecting data from patients and medical students. The Journal of Sexual Medicine, 6(2), 362-368.

World Health Organization. (2006). The World Health Report 2006 - working together for health. Retrieved from http://www.who.int/whr/2006/en/

Xie, Y., Shi, L., Xiong, X., Wu, E., Veasley, C., \& Dade, C. (2012). Economic burden and quality of life of vulvodynia in the United States. Current Medical Research and Opinion, 28(4), 601-608. 